OPEN ACCESS

Edited by:

Yuheng Luo,

Sichuan Agricultural University, China

Reviewed by:

Tarique Hussain,

Pakistan Institute of Engineering and Applied Sciences, Pakistan

Tao Yang,

University of Florida, United States

Deguang Song,

Yale School of Medicine,

Yale University, United States

*Correspondence:

Re-jun Fang

fangri63@126.com

Guang-hai QI

qiguanghai@caas.cn

Specialty section:

This article was submitted to

Gastrointestinal Sciences,

a section of the journa

Frontiers in Physiology

Received: 30 September 2018

Accepted: 31 December 2018

Published: 17 January 2019

Citation:

Li C-I, Wang J, Zhang H-j,

Wu S-g, Hui Q-r, Yang C-b, Fang R-

and Qi G-h (2019) Intestinal

Morphologic and Microbiota Responses to Dietary Bacillus spp.

in a Broiler Chicken Model.

Front. Physiol. 9:1968.

doi: 10.3389/fphys.2018.01968

\section{Intestinal Morphologic and Microbiota Responses to Dietary Bacillus spp. in a Broiler Chicken Model}

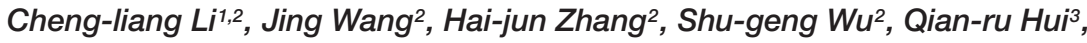 \\ Cheng-bo Yang ${ }^{3}$, Re-jun Fang ${ }^{* *}$ and Guang-hai Qi',2*
}

${ }^{1}$ College of Animal Science and Technology, Hunan Agricultural University, Changsha, China, ${ }^{2}$ Key Laboratory of Feed Biotechnology of Ministry of Agriculture and Rural Affairs, Feed Research Institute, Chinese Academy of Agricultural Sciences, Beijing, China, ${ }^{3}$ Department of Animal Science, Faculty of Agricultural and Food Sciences, University of Manitoba, Winnipeg, MB, Canada

Dietary inclusion of probiotic Bacillus spp. beneficially affect the broiler chickens by balancing the properties of the indigenous microbiota causing better growth performance. The effects of three Bacillus spp. on the growth performance, intestinal morphology and the compositions of jejunal microflora were investigated in broiler chickens. A total of 480 1-day-old male Arbor Acres broilers were randomly divided into four groups. All groups had six replicates and 20 birds were included in each replicate. The control birds were fed with a corn-soybean basal diet, while three treatment diets were supplemented with Bacillus coagulans TBC169, B. subtilis PB6, and B. subtilis DSM32315 with a dosage of $1 \times 10^{9} \mathrm{cfu} / \mathrm{kg}$, respectively. The experiment lasted for 42 days. The compositions and diversity of jejunal microflora were analyzed by MiSeq high-throughput sequencing. The B. coagulans TBC169 group showed marked improvements of growth performance, nutrient digestibility and intestinal morphology compared with the other $B$. subtilis treatments. B. coagulans TBC169 supplementation improved the average body weight (BW), average daily weight gain (ADG), total tract apparent digestibility of crude protein and gross energy (GE), and reduced feed conversion rate (FCR) compared with the control group $(P<0.05)$. The villus height to crypt depth ratio $(\mathrm{VH} / \mathrm{CD})$ of jejunum and duodenum was increased in the birds fed with $B$. coagulans TBC169 compared with the control group $(P<0.05)$. However, two $B$. subtilis treatments presented more positive variation of the jejunum microflora of chickens than that in the B. coagulans TBC169 group. B. subtilis PB6 and $B$. subtilis DSM32315 treatments improved the diversity of jejunal microbiota on day 21 compared with the control $(P<0.05)$, while which were decreased on day 42 $(P<0.05)$. The supplementation with $B$. coagulans TBC169 significantly improved the proportion of Firmicutes, otherwise two $B$. subtilis significantly improved the proportion of Proteobacteria, Bacteroidetes, Actinobacteria, and Acidobacteria at the phylum level during starter phase and decreased the proportion of Bacteroidetes during growing phase compared with the control. The supplementation with B.subtilis DSM32315 significantly improved the proportion of Clostridiales during starter phase, whereas 
two B. subtilis significantly improved the proportion of Pseudomonas, Burkholderia, Prevotella, DA101 during growing phase at the genus level compared with the control. In conclusion, the dietary supplementation with probiotic Bacillus spp. strains improved body weight and intestinal morphology in broiler chickens, which might be associated with the gut microbiota.

Keywords: probiotics, growth performance, intestinal morphology, jejunum microbiota, broiler

\section{INTRODUCTION}

Broiler chickens have been reared and consumed widely around the world since they can provide high-quality meat and eggs for human beings. During the last 6 or 7 decades, with the development of production system, chickens can convert feed into muscle mass efficiently (Clavijo and Flórez, 2017). The worldwide demand for chicken meat continues to grow considerably (Tallentire et al., 2018). Meanwhile, because of the detrimental side effects of antibiotics on both poultry products and human well-being, an increasing number of countries have implemented the withdrawal of antibiotic growth promoters (AGPs), which was previously recognized as growth promoters to boost animal growth performance and inhibit the spread of certain diseases (Mashayekhi et al., 2018).

Probiotics are non-pathogenic bacterial cultures that can adjust intestinal microflora and in turn improve the gastrointestinal environment of the host. In addition, probiotics have positive impacts on colonized beneficial bacterial and growth performance in broilers and pigs (Jeong and Kim, 2014; Valeriano et al., 2017). Noticeably, probiotics, as the alternatives for antibiotics used to prevent poultry diseases and improve production performance, have been demonstrated to be beneficial to chickens' growth performance and health, such as the increases of body weight (BW), feed conversion efficiency, immune response, resistance to bacterial infection, and regulation of intestinal microflora (Xu et al., 2012; Cao et al., 2013; Song et al., 2014; Clavijo and Flórez, 2017; Haque et al., 2017; Hussain et al., 2017a; Azad et al., 2018; Mashayekhi et al., 2018).

Presently, spore-forming bacteria, such as Bacillus spp. including Bacillus subtilis, B. coagulans, and B. licheniformis etc. have been widely used as commercialized probiotic products for humans and animals (Barbosa et al., 2005; Zhang et al., 2013; Park and Kim, 2014; Haque et al., 2017; Xu et al., 2017). Bacillus spp. have been also considered to be promising probiotics, due to the high stability of spores, which is resistant to high temperature and harsh gastrointestinal conditions during feed processing and that can confer health benefits to the host (Mazanko et al., 2017). Previous study showed that B. subtilis and $B$. coagulans had positive effects on tilapia growth and immune response (Zhou et al., 2010). Moreover, it has been reported that dietary supplementation with $B$. subtilis exerted a beneficial role in the digestibility and intestinal microbes of weaning piglets, and finally improving their growth performance (Tsukahara et al., 2013). Lee S.H. et al. (2014) suggested that dietary supplementation with $B$. subtilis in pigs exhibited significant effects on gut morphology, microbiota compositions and immune function. Feeding broilers with $B$. coagulans diets can improve the feed conversion ratio (FCR) and beneficially modulate the composition of the microflora, which markedly enhanced the relative abundance of lactobacilli and tended to lower coliform bacteria composition (Hung et al., 2012). As a result, oral administration with $B$. subtilis and $B$. coagulans may have potential to improve the growth state, intestinal function and microflora compositions of broilers. But many studies reported that probiotics had no significant effect on growth in broilers (Arslan et al., 2004; Chitra et al., 2004; Das et al., 2005).

Researches on the classification and identification of intestinal microbes in poultries were conducted progressively because of the conventional molecular ecology techniques such as denaturing gradient gel electrophoresis (DGGE) fingerprints (Li et al., 2017; Yang et al., 2018). However, these techniques can just detect minority dominant population and it is difficult to study the composition, structure and diversity of microflora. In recent years, with the technical development, the high-throughput sequencing has been promoted widely, which realized the parallel comparison among multiple samples on the level of metagenome, and can detect the microbial diversity including rare species more sensitively (Zhou et al., 2011; Micucci et al., 2017; Yin et al., 2017).

However, as three typical strains of $B$. subtilis and B. coagulans, B. coagulans TBC169, B. subtilis PB6 and B. subtilis DSM32315, have been rarely studied as probiotics to improve the wellbeing of broiler chickens. Furthermore, little is known about the effects of $B$. subtilis and B. coagulans on gastrointestinal tract (GIT) microflora compositions and intestinal morphology. Therefore, the objective of this study was to evaluate the effects of $B$. coagulans TBC169, B. subtilis PB6 and B. subtilis DSM32315 supplementation on the growth performance, nutrient utilization and morphological development of the small intestine in broilers. The microflora compositions in the jejunum of broilers were further studied by MiSeq high-throughput sequencing to reveal the relationship among the growth performance, intestinal morphology and microflora in order to promote new evidences for the mechanism of action of these probiotics.

\section{MATERIALS AND METHODS}

\section{Probiotics Strains}

Three kinds of commercial probiotics strains were $B$. coagulans TBC169, B. subtilis PB6 and B. subtilis DSM32315. The probiotic product contains at least $2.0 \times 10^{9} \mathrm{cfu} / \mathrm{g}$ of Bacillus spp. and was stored in a sterilized container. The concentration of each Bacillus spp. product was $1 \times 10^{9} \mathrm{cfu} / \mathrm{kg}$. 


\section{Experimental Design and Dietary Treatments}

A total of 480 healthy 1-day-old male Arbor Acres (Isolauri et al., 2001) broilers (Beijing Huadu Broiler Company, Beijing, China) with average body weight of $48 \mathrm{~g}$ were randomly allotted into four treatments. There were six replicates $(20$ birds per replicate) for each treatment. The diets, without any antibiotics and growth promoters, were based on cornsoybean meal and formulated to meet starter (days 1-21) and grower-finisher (days 22-42) growth requirements (Table 1) (Chinese Feeding Standard of Chicken, Ministry of Agriculture of China, 2004; National Research Council, 1994). Dietary treatments consisted of basal diet with $B$. coagulans TBC169; basal diet with B. subtilis PB6; (3) basal diet with B. subtilis DSM32315 and the basal diet with no probiotic supplementation was set as the control. Treatments were supplemented with $200 \mathrm{mg} / \mathrm{kg}$ Bacillus spp. All experimental protocols were approved by Animal Care and Use Committee of the Feed Research Institute of the Chinese Academy of Agricultural Sciences. All management of birds in this study was according to the guideline of raising AA broilers (Delezie et al., 2012).

TABLE 1 | Composition and nutrient levels of the basal diet (air-dry basis, \%).

\begin{tabular}{|c|c|c|}
\hline Items & Starting (days 1-21) & Growing (days 22-42) \\
\hline \multicolumn{3}{|l|}{ Ingredients } \\
\hline Corn & 56.37 & 63.08 \\
\hline Soybean meal & 36.56 & 29.24 \\
\hline Soybean oil & 3.00 & 3.50 \\
\hline $\mathrm{CaHPO}_{4}$ & 1.24 & 1.61 \\
\hline Limestone & 1.61 & 1.18 \\
\hline $\mathrm{NaCl}$ & 0.35 & 0.35 \\
\hline DL-Met & 0.27 & 0.30 \\
\hline L-Lys.HCl & 0.19 & 0.27 \\
\hline L-Thr & 0.09 & 0.15 \\
\hline Vitamin premix ${ }^{1}$ & 0.02 & 0.02 \\
\hline Mineral premix ${ }^{2}$ & 0.20 & 0.20 \\
\hline $50 \%$ choline chloride & 0.10 & 0.10 \\
\hline Total & 100 & 100 \\
\hline \multicolumn{3}{|l|}{ Calculated nutrient levels } \\
\hline AME (MJ/kg) & 12.55 & 12.97 \\
\hline Crude protein, \% & 21.00 & 19.00 \\
\hline Calcium, \% & 1.00 & 0.90 \\
\hline Available phosphorus, \% & 0.45 & 0.40 \\
\hline Lysine, \% & 1.15 & 1.05 \\
\hline Methionine, \% & 0.55 & 0.48 \\
\hline Methionine + cystine, \% & 0.92 & 0.84 \\
\hline Threonine, \% & 0.82 & 0.69 \\
\hline Tryptophan, \% & 0.24 & 0.22 \\
\hline
\end{tabular}

${ }^{1}$ The vitamin premix supplied the following per $\mathrm{kg}$ of complete feed: vitamin A, 12,500 IU; vitamin D3, 2,500 IU; vitamin K3, $2.65 \mathrm{mg}$; vitamin B1, $2 \mathrm{mg}$; vitamin B2, $6 \mathrm{mg}$; vitamin B12, $0.025 \mathrm{mg}$; vitamin E, $30 \mathrm{IU}$; biotin, $0.0325 \mathrm{mg}$; folic acid, $1.25 \mathrm{mg}$; pantothenic acid, $12 \mathrm{mg}$; niacin, $50 \mathrm{mg}$. ${ }^{2}$ The mineral premix supplied the following per kg of complete feed: $\mathrm{Cu}, 8 \mathrm{mg} ; \mathrm{Zn}, 75 \mathrm{mg}$; Fe, $80 \mathrm{mg}$; Mn, $100 \mathrm{mg}$; Se, $0.15 \mathrm{mg} ; \mathrm{l}, 0.35$.

\section{Growth Performance}

Body weight and feed intake were recorded (days 1-21 and day 22-42). Average daily feed intake (ADFI), average daily weight gain (ADG), and feed conversion ratio (FCR, feed/weight gain, $\mathrm{g} / \mathrm{g}$ ) were calculated.

\section{Apparent Total Tract Nutrients Digestibility}

All droppings (five pens for each treatment) were sampled daily for 5 consecutive days from day 37 in this study. Dry matter $(\mathrm{DM})$, crude protein $(\mathrm{CP})$, crude ash, calcium $(\mathrm{Ca})$ and phosphorus $(\mathrm{P})$ in the diet and excreta samples were analyzed according to the method of the Association of Official Analytical Chemists International, 2007. Gross energy (GE) of these samples was tested by a bomb calorimetry (Gallenkamp Autobomb, London, United Kingdom).

\section{Histology and Morphometric Analysis of the Intestine}

On days 21 and 42, five chicks close to average weight from each treatment were killed and intestinal sections were fixed to measure the intestinal villus height (VH) and crypt depth (CD) (Sun et al., 2005).

\section{Sampling, DNA Extraction and PCR (Polymerase Chain Reaction) Amplification}

Four jejunum samples each treatment were selected from the five chickens slaughtered above as the next study about microbiota on days 21 and 42 . The jejunum was ligated by light twine, removed and finally collected in cryogenic vials. All samples were quickly put into liquid nitrogen and stored at $-80^{\circ} \mathrm{C}$ until DNA extraction. The jejunum content of each group was collected and homogenized for further experiments.

Total jejunal bacterial genomic DNA was extracted from content samples by using the Fast DNA SPIN extraction kits (MP Biomedicals, Santa Ana, CA, United States) following the manufacturer's instructions. Subsequently, The quantity and quality of extracted DNAs were measured using a NanoDrop ND1000 spectrophotometer (Thermo Fisher Scientific, Waltham, MA, United States) and agarose gel electrophoresis, respectively. The DNA was used as templates to amplify the V4 hyper variable region of $16 \mathrm{~S}$ rRNA gene by PCR using barcoded fusion primers [forward primer: 520 (5-AYTGGGYDTAAAGNG-3), reverse primer: 802 (5-TACNVGGGTATCTAATCC-3)]. Sample-specific 7-bp barcodes were incorporated into the primers for multiplex sequencing. The PCR components contained $5 \mu \mathrm{l}$ of Q5 reaction buffer $(5 \times), 5 \mu \mathrm{l}$ of Q5 High-Fidelity GC buffer $(5 \times), 0.25 \mu \mathrm{l}$ of Q5 High-Fidelity DNA Polymerase ( $5 \mathrm{U} / \mu \mathrm{l}), 2 \mu \mathrm{l}(2.5 \mathrm{mM})$ of dNTPs, $1 \mu \mathrm{l}(10 \mu \mathrm{M})$ of each Forward and Reverse primer, $2 \mu \mathrm{l}$ of DNA Template, and $8.75 \mu \mathrm{l}$ of ddH2O. Thermal cycling consisted of initial denaturation at $98^{\circ} \mathrm{C}$ for $2 \mathrm{~min}$, followed by 25 cycles consisting of denaturation at $98^{\circ} \mathrm{C}$ for $15 \mathrm{~s}$, annealing at $55^{\circ} \mathrm{C}$ for $30 \mathrm{~s}$, and extension at $72^{\circ} \mathrm{C}$ for $30 \mathrm{~s}$, with a final extension of $5 \mathrm{~min}$ at $72^{\circ} \mathrm{C}$. PCR amplicons were purified with Agencourt AMPure Beads (Beckman Coulter, Indianapolis, IN, United States) and 
quantified using the PicoGreen dsDNA Assay Kit (Invitrogen, Carlsbad, CA, United States). The final sequencing library was prepared by mixing the equal amount of purified PCR products, followed by an end reparation with the addition of a poly (A) tail, and the amplicons were connected with each other with the sequencing adapters.

\section{MiSeq High-Throughput Sequencing and Analysis}

Purified PCR products from the 31 samples were mixed with equal concentrations, which were performed using the Illumina MiSeq platform with MiSeq Reagent Kit v3 at Shanghai Personal Biotechnology Co., Ltd. (Shanghai, China). Sequencing libraries were generated and analyzed according to previous studies (Yin et al., 2017, 2018a,b).

The Quantitative Insights Into Microbial Ecology (QIIME, v1.8.0) pipeline was employed to process the sequencing data, as previously described (Caporaso et al., 2010). Briefly, raw sequencing reads with exact matches to the barcodes were assigned to respective samples and identified as valid sequences. The low-quality sequences were filtered through following criteria (Gill et al., 2006; Chen and Jiang, 2014): sequences that had a length of $<150 \mathrm{bp}$, sequences that had average Phred scores of $<20$, sequences that contained ambiguous bases, and sequences that contained mononucleotide repeats of $>8 \mathrm{bp}$. Paired-end reads were assembled using FLASH (Magoč and Salzberg, 2011). After chimera detection, the remaining highquality sequences were clustered into operational taxonomic units (OTUs) at 97\% sequence identity by UCLUST (Edgar, 2010). A representative sequence was selected from each OTU using default parameters. OTU taxonomic classification was conducted by BLAST searching the representative sequences set against the Greengenes Database (DeSantis et al., 2006) using the best hit (Altschul et al., 1997). An OTU table was further generated to record the abundance of each OTU in each sample and the taxonomy of these OTUs. OTUs containing less than $0.001 \%$ of total sequences across all samples were discarded. To minimize the difference of sequencing depth across samples, an averaged, rounded rarefied OTU table was generated by averaging 100 evenly resampled OTU subsets under the $90 \%$ of the minimum sequencing depth for further analysis.

To investigate the diversity of the jejunum microbiota, alpha diversity analysis was made by using the OUT table. Diversity indexes (Shannon, Simpson) (Chao and ShenMing, 1992) were calculated. Sequence data analyses were mainly performed using QIIME and R packages (v3.2.0). OTU-level ranked abundance curves were generated to compare the richness and evenness of OTUs among samples. Beta diversity analysis was performed to investigate the structural variation of microbial communities across samples using UniFrac distance metrics (Lozupone and Knight, 2005; Lozupone et al., 2007) and visualized via principal coordinate analysis (PCoA) and non-metric multidimensional scaling (NMDS) (Ramette, 2007). The significance of differentiation of microbiota structure among groups was assessed by PERMANOVA (McArdle and Anderson, 2001) and ANOSIM (Clarke, 1993; Warton et al., 2012) using R package "vegan". Taxa abundances at the phylum, class, order, family and genus levels were statistically compared among groups by LEfSe was performed to detect differentially abundant taxa across groups using the default parameters (Segata et al., 2011). PLS-DA was also introduced as a supervised model to reveal the microbiota variation among groups, using the "plsda" function in R package "mixOmics" (Chen et al., 2011). Spearman correlation coefficients were calculated for correlation between growth performance (i.e., $\mathrm{BW}$ and $\mathrm{ADG}$ ) and change of microbiota, which aimed to establish suitable microbial composition for better growth performance.

TABLE 2 | Effect of dietary probiotic supplementation on growth performance of broiler chickens ${ }^{1,2,3}$.

\begin{tabular}{|c|c|c|c|c|c|}
\hline Items ${ }^{4}$ & Control & Bacillus coagulans TBC169 & Bacillus subtilis PB6 & Bacillus subtilis DSM32315 & $p$-value \\
\hline Initial BW (g) & $48.16 \pm 0.12$ & $47.98 \pm 0.21$ & $48.09 \pm 0.15$ & $48.08 \pm 0.12$ & 0.866 \\
\hline BW on day 21 (g) & $918.44 \pm 17.11^{a}$ & $986.72 \pm 19.30^{\circ}$ & $963.93 \pm 15.14^{\mathrm{bc}}$ & $947.54 \pm 7.53^{a b c}$ & 0.035 \\
\hline BW on day 42 (g) & $2715.49 \pm 34.71^{a}$ & $2849.49 \pm 86.35^{c}$ & $2786.96 \pm 52.38^{a b}$ & $2741.20 \pm 42.35^{\mathrm{ab}}$ & 0.024 \\
\hline \multicolumn{6}{|c|}{ Starter phase (days 1-21) } \\
\hline$A D G(g)$ & $41.48 \pm 0.84^{a}$ & $44.70 \pm 0.92^{c}$ & $43.61 \pm 0.72^{\mathrm{ac}}$ & $42.83 \pm 0.36^{\mathrm{ac}}$ & 0.039 \\
\hline ADFI $(g)$ & $56.08 \pm 0.83$ & $56.59 \pm 0.73$ & $56.97 \pm 0.83$ & $55.30 \pm 1.02$ & 0.561 \\
\hline FCR $(F / G, g / g)$ & $1.36 \pm 0.04$ & $1.27 \pm 0.02$ & $1.31 \pm 0.02$ & $1.29 \pm 0.02$ & 0.142 \\
\hline \multicolumn{6}{|c|}{ Grower phase (days 22-42) } \\
\hline ADG $(g)$ & $85.58 \pm 1.45$ & $94.32 \pm 4.17$ & $86.81 \pm 2.43$ & $85.41 \pm 1.70$ & 0.086 \\
\hline ADFI (g) & $149.42 \pm 3.89$ & $150.93 \pm 5.96$ & $154.22 \pm 3.74$ & $144.34 \pm 3.56$ & 0.254 \\
\hline FCR $(F / G, g / g)$ & $1.75 \pm 0.03$ & $1.67 \pm 0.05$ & $1.78 \pm 0.02$ & $1.69 \pm 0.06$ & 0.223 \\
\hline \multicolumn{6}{|c|}{ Whole phase (days 1-42) } \\
\hline ADG $(g)$ & $63.52 \pm 0.83^{a}$ & $69.51 \pm 2.05^{c}$ & $65.21 \pm 1.25^{\mathrm{ab}}$ & $64.12 \pm 1.01^{\mathrm{ab}}$ & 0.024 \\
\hline $\operatorname{ADFI}(\mathrm{g})$ & $108.25 \pm 2.89$ & $108.99 \pm 4.51$ & $107.46 \pm 2.65$ & $105.16 \pm 3.67$ & 0.590 \\
\hline FCR (F/G, g/g) & $1.70 \pm 0.03$ & $1.61 \pm 0.03$ & $1.65 \pm 0.02$ & $1.64 \pm 0.07$ & 0.536 \\
\hline
\end{tabular}

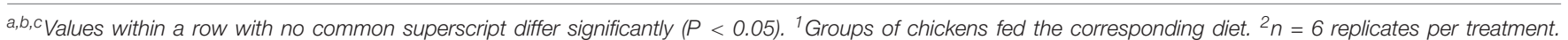

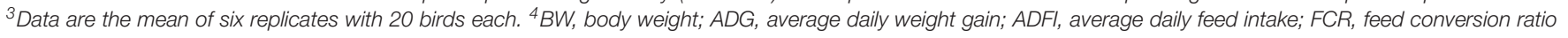
(feed:gain, $g: g$ ). 


\section{Statistical Analysis}

Data were analyzed by one-way ANOVA and subsequent Duncan's multiple range test (SPSS 19.0 for Windows; SPSS Inc., Chicago, IL, United States). Results are expressed as means \pm SEM. Probability values of less than or equal to 0.05 $(P \leq 0.05)$ were considered significant, whereas a trend for a treatment effect was noted for $P \leq 0.10$.

\section{RESULTS}

\section{Growth Performance}

The effects of dietary probiotics supplementation on the growth performance of broilers were shown in Table 2 . The supplementation with $B$. coagulans TBC169 in feeds increased BW on days 21 and $42(P<0.01)$ and ADG $(P<0.01)$ during starter phase (days 1-21) and the whole phase (days 1-42) compared with the control. The supplementation with B. subtilis PB6 in diets increased BW on day $21(P<0.05)$.
Results showed that compared with subtilis PB6 group and $B$. subtilis DSM32315 group, the addition of $B$. coagulans TBC169 in broiler's diets improved $(P<0.05)$ BW on day 42 and ADG during the overall period (days 1-42). Dietary probiotic supplementations tended to increase the ADG $(P=0.086)$ during grower phase (days 22-42). However, ADFI and FCR were no difference $(P>0.05)$ among the groups of $B$. coagulans TBC169, B. subtilis $\mathrm{PB} 6$ and $B$. subtilis DSM32315.

\section{Apparent Total Tract Nutrient Digestibility}

Dietary supplementation with different Bacillus spp. influenced $(P=0.045, P=0.011$, respectively) the apparent total tract digestibility of GE and CP during the feeding phase (Table 3). Supplementation with B. coagulans TBC169 and B. subtilis DSM32315 improved $(P<0.05)$ the apparent total tract digestibility of $\mathrm{GE}$ and $\mathrm{CP}$ compared with the control group. Supplementation with $B$. coagulans

TABLE 3 | Effect of dietary probiotic supplementation on the apparent total tract nutrients digestibility in broiler chickens (\%) ${ }^{1}$.

\begin{tabular}{|c|c|c|c|c|c|}
\hline Item & Control & Bacillus Coagulans TBC169 & Bacillus subtilis PB6 & Bacillus subtilis DSM32315 & $p$-value \\
\hline Dry matter & $72.48 \pm 0.09$ & $72.72 \pm 0.98$ & $71.23 \pm 0.38$ & $73.14 \pm 1.84$ & 0.514 \\
\hline Gross energy & $77.31 \pm 0.40^{\mathrm{a}}$ & $79.64 \pm 0.94^{b}$ & $77.84 \pm 0.27^{a b}$ & $79.87 \pm 0.85^{b}$ & 0.045 \\
\hline Crude protein & $57.83 \pm 0.50^{a}$ & $64.31 \pm 1.89^{c}$ & $59.99 \pm 0.83^{a b}$ & $63.96 \pm 1.50^{b c}$ & 0.011 \\
\hline Crude ash & $16.18 \pm 1.62$ & $24.96 \pm 1.01$ & $17.56 \pm 0.98$ & $22.20 \pm 0.73$ & 0.133 \\
\hline $\mathrm{Ca}$ & $37.07 \pm 2.12$ & $44.06 \pm 2.47$ & $38.50 \pm 2.38$ & $38.50 \pm 4.55$ & 0.330 \\
\hline$P$ & $45.42 \pm 2.39$ & $49.50 \pm 2.84$ & $43.64 \pm 1.94$ & $43.73 \pm 3.64$ & 0.380 \\
\hline
\end{tabular}

a, b,c Means values in the same row with different letters differ significantly $(P<0.05) .{ }^{1} n=6$ replicates per treatment.

TABLE 4 | Effect of dietary Bacillus spp. supplementation on the intestinal morphology of broiler chickens on the age of days 21 and $42^{1,2}$.

\begin{tabular}{|c|c|c|c|c|c|c|}
\hline & Item & Control & Bacillus coagulans TBC169 & Bacillus subtilis PB6 & Bacillus subtilis DSM32315 & $p$-value \\
\hline \multicolumn{7}{|l|}{ Day 21} \\
\hline \multirow[t]{3}{*}{ Duodenum } & Villous & $1468.87 \pm 111.43$ & $1740.37 \pm 55.37$ & $1642.75 \pm 121.67$ & $1507.82 \pm 79.83$ & 0.259 \\
\hline & Crypt & $291.19 \pm 36.13$ & $208.18 \pm 41.09$ & $223.7 \pm 15.5$ & $205.07 \pm 34.61$ & 0.236 \\
\hline & Villous/crypt & $5.33 \pm 0.72$ & $9.3 \pm 1.66$ & $7.56 \pm 0.88$ & $7.98 \pm 1.1$ & 0.122 \\
\hline \multirow[t]{3}{*}{ Jejunum } & Villous & $1154.92 \pm 118.33$ & $1491.31 \pm 99.2$ & $1260.29 \pm 104.58$ & $1313.77 \pm 78.41$ & 0.167 \\
\hline & Crypt & $240.49 \pm 31.76$ & $145.83 \pm 8.16$ & $196.18 \pm 24.65$ & $162.34 \pm 33.74$ & 0.068 \\
\hline & Villous/crypt & $5.23 \pm 0.96^{a}$ & $10.47 \pm 1.16^{b}$ & $6.69 \pm 0.85^{a b}$ & $9.31 \pm 2.97^{\mathrm{ab}}$ & 0.050 \\
\hline \multirow[t]{3}{*}{ lleum } & Villous & $883.62 \pm 80.68$ & $838.41 \pm 106.92$ & $811.3 \pm 67.72$ & $774.95 \pm 94.7$ & 0.849 \\
\hline & Crypt & $178.7 \pm 5.47$ & $151.53 \pm 13.94$ & $154.58 \pm 21.12$ & $133.04 \pm 8.52$ & 0.324 \\
\hline & Villous/crypt & $4.95 \pm 0.46$ & $5.5 \pm 0.3$ & $5.41 \pm 0.52$ & $5.96 \pm 1.1$ & 0.772 \\
\hline \multicolumn{7}{|l|}{ Day 42} \\
\hline \multirow[t]{3}{*}{ Duodenum } & Villous & $1482.97 \pm 29.07$ & $1627.7 \pm 139.96$ & $1394.45 \pm 81.06$ & $1465.38 \pm 78.23$ & 0.413 \\
\hline & Crypt & $287.63 \pm 90.62$ & $227.1 \pm 33.3$ & $265.24 \pm 16.79$ & $243.82 \pm 31.1$ & 0.760 \\
\hline & Villous/crypt & $6.17 \pm 1.65$ & $7.72 \pm 1.14$ & $5.35 \pm 0.51$ & $6.27 \pm 0.73$ & 0.363 \\
\hline \multirow[t]{3}{*}{ Jejunum } & Villous & $1019.34 \pm 112.86^{a}$ & $1354.03 \pm 101.56^{\mathrm{b}}$ & $1493.5 \pm 105.49^{c}$ & $1080.81 \pm 85.51^{\mathrm{ab}}$ & 0.032 \\
\hline & Crypt & $214.93 \pm 18.01$ & $197.79 \pm 16.48$ & $217.3 \pm 34.79$ & $180.93 \pm 7.47$ & 0.617 \\
\hline & Villous/crypt & $4.74 \pm 0.35^{a}$ & $6.9 \pm 0.41^{b}$ & $7.21 \pm 1.11^{\mathrm{b}}$ & $5.97 \pm 0.33^{a b}$ & 0.042 \\
\hline \multirow[t]{3}{*}{ lleum } & Villous & $856.21 \pm 66.26$ & $926.34 \pm 65.43$ & $867.31 \pm 79.72$ & $807.74 \pm 68.47$ & 0.761 \\
\hline & Crypt & $171.24 \pm 21.34$ & $144.34 \pm 32.39$ & $187.35 \pm 26.6$ & $166.65 \pm 26.5$ & 0.766 \\
\hline & Villous/crypt & $5.24 \pm 0.77$ & $6.98 \pm 1.26$ & $4.96 \pm 0.77$ & $5.34 \pm 0.88$ & 0.503 \\
\hline
\end{tabular}

a,b,c Means with a row with no common superscripts differ significantly $(P<0.05) .{ }^{1}$ Groups of chickens fed the corresponding diet. ${ }^{2} n=5$ replicates per treatment. 


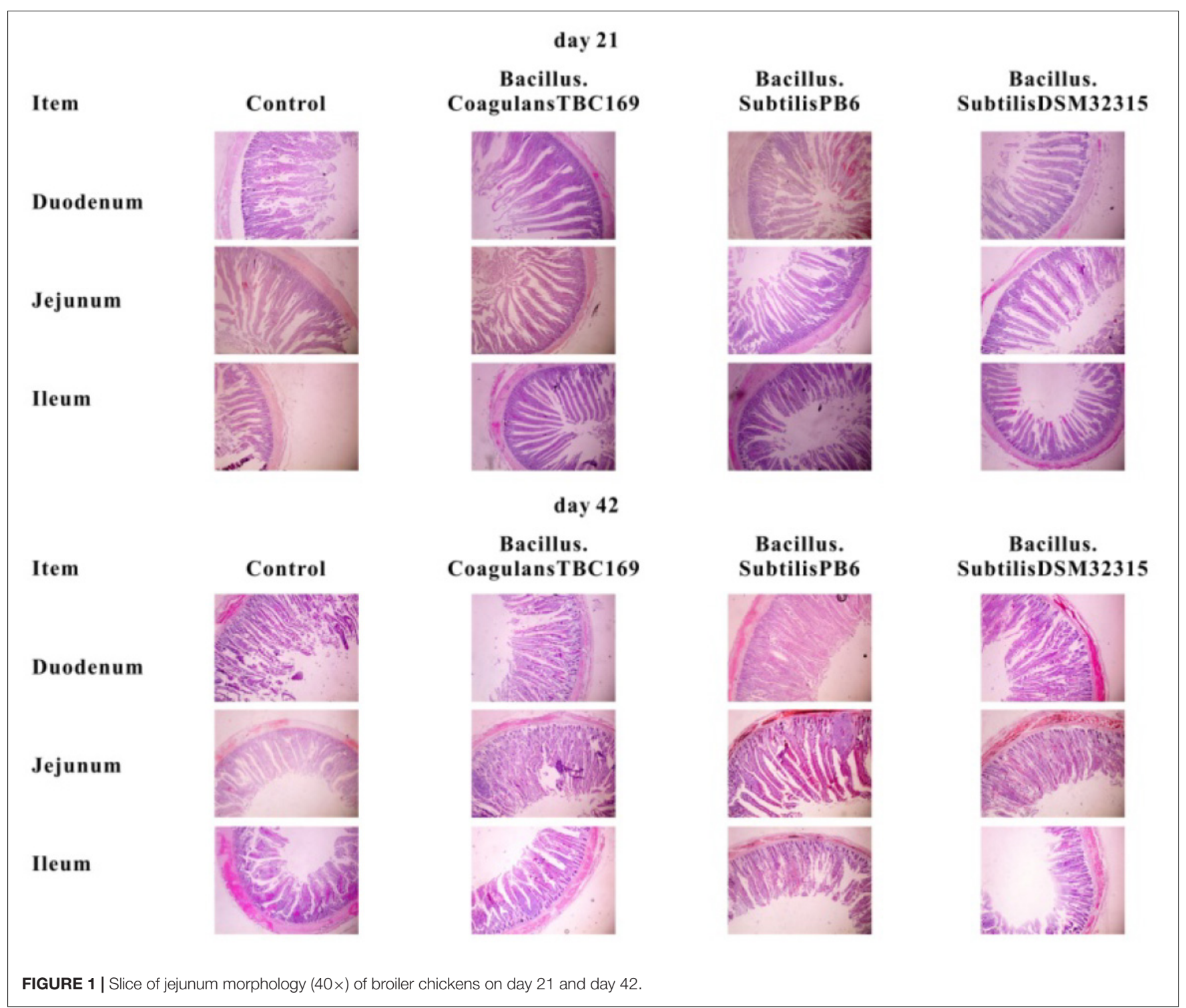

TBC169 increased $(P<0.05)$ the apparent total tract digestibility of CP compared with the B. subtilis PB6 group. There were no statistical differences $(P>0.05)$ in the apparent total tract digestibility of $\mathrm{DM}, \mathrm{Ca}$ and $\mathrm{P}$ among groups.

\section{Intestinal Morphology}

The intestinal morphology of small intestine of broilers in different treatments on days 21 and 42 was shown in Table 4 and Figure 1. On day 21, Dietary supplementation with Bacillus spp. tended to influence $(P=0.068)$ the $\mathrm{CD}$ of jejunum. The jejunal CD of $B$. coagulans TBC169 group was lower $(P<0.05)$ than those of the control group. Dietary supplementation with Bacillus spp. increased $(P=0.05)$ the $\mathrm{VH} / \mathrm{CD}$ of jejunum. The jejunal $\mathrm{VH} / \mathrm{CD}$ ratio of $B$. coagulans $\mathrm{TBC} 169$ group was higher $(P<0.05)$ than those of the control group. There were no differences $(P>0.05)$ among other groups. On day 42 , Dietary supplementation with Bacillus spp. influenced $(P<0.05)$ the VH and $\mathrm{VH} / \mathrm{CD}$ ratio of jejunum. The jejunal $\mathrm{VH}$ of $B$. coagulans TBC169 group and B. subtilis $\mathrm{PB} 6$ group were higher $(P<0.05$ and $P<0.01)$ than that of the control group. The jejunal $\mathrm{VH} / \mathrm{CD}$ ratio of $B$. coagulans $\mathrm{TBC} 169$ group and B. subtilis $\mathrm{PB} 6$ group were greater $(P<0.05)$ than that of control group. The jejunal VH of $B$. subtilis $\mathrm{PB} 6$ group were higher $(P<0.05)$ than those of B. coagulans TBC169 group and B. subtilis DSM32315 group. Meanwhile, there were no differences $(P>0.05)$ among other groups. The dietary probiotics supplementation did not affect $(P>0.05)$ the intestinal parameters in the ileum of broilers.

\section{Impact of Bacillus spp. Supplementation on Abundance of Microbial Taxa}

Based on the V4 region of the 16S rDNA sequence, 114506 amplicons were used for this study with the average of 
TABLE 5 | The effect of different Bacillus spp. on OTUs of gut microbiota of broiler chickens on days 21 and $42^{1}$.

\begin{tabular}{|c|c|c|c|c|c|}
\hline Items & Control & Bacillus coagulans TBC169 & Bacillus.Subtilis PB6² & Bacillus subtilis DSM32315 & $p$-value \\
\hline \multicolumn{6}{|l|}{ Day 21} \\
\hline Phylum & $456 \pm 103^{a}$ & $383 \pm 44^{a}$ & $777 \pm 15^{c}$ & $871 \pm 62^{c}$ & 0.001 \\
\hline Class & $456 \pm 102^{a}$ & $384 \pm 44^{a}$ & $773 \pm 16^{c}$ & $866 \pm 62^{c}$ & 0.001 \\
\hline Order & $428 \pm 80^{a}$ & $374 \pm 40^{\mathrm{a}}$ & $738 \pm 16^{c}$ & $816 \pm 62^{c}$ & 0.000 \\
\hline Family & $334 \pm 41^{\mathrm{a}}$ & $324 \pm 27^{a}$ & $557 \pm 20^{c}$ & $604 \pm 47^{c}$ & 0.000 \\
\hline Genus & $203 \pm 13^{a}$ & $212 \pm 10^{a}$ & $305 \pm 7^{c}$ & $317 \pm 24^{c}$ & 0.000 \\
\hline Species & $51 \pm 6$ & $57 \pm 5$ & $52 \pm 2$ & $55 \pm 4$ & 0.804 \\
\hline Unclassified & $50 \pm 7^{a}$ & $21 \pm 5^{c}$ & $15 \pm 3^{\mathrm{cd}}$ & $6 \pm 1^{d}$ & 0.000 \\
\hline \multicolumn{6}{|l|}{ Day 42} \\
\hline Phylum & $2171 \pm 55^{a}$ & $1771 \pm 263^{a b}$ & $1321 \pm 365^{\mathrm{bcd}}$ & $636 \pm 123^{d}$ & 0.004 \\
\hline Class & $2138 \pm 54^{a}$ & $1748 \pm 259^{a b}$ & $1308 \pm 359^{b c d}$ & $633 \pm 122^{d}$ & 0.004 \\
\hline Order & $1911 \pm 41^{a}$ & $1580 \pm 229^{a b}$ & $1202 \pm 319^{b c d}$ & $586 \pm 107^{d}$ & 0.004 \\
\hline Family & $1285 \pm 19^{a}$ & $1078 \pm 145^{a b}$ & $788 \pm 180^{\mathrm{bcd}}$ & $439 \pm 69^{d}$ & 0.002 \\
\hline Genus & $582 \pm 7^{\mathrm{a}}$ & $506 \pm 59^{a b}$ & $387 \pm 76^{\mathrm{bcd}}$ & $242 \pm 25^{d}$ & 0.002 \\
\hline Species & $86 \pm 2^{a}$ & $77 \pm 10^{a}$ & $65 \pm 12^{\mathrm{ac}}$ & $39 \pm 5^{c}$ & 0.010 \\
\hline Unclassified & $7 \pm 0.3^{a}$ & $8 \pm 0.4^{a}$ & $4 \pm 1^{c}$ & $4 \pm 0.5^{c}$ & 0.001 \\
\hline
\end{tabular}

a,b,c,d Means within a row with no common superscripts differ significantly $(P<0.05) .{ }^{1} n=4$ replicates per treatment. ${ }^{2} n=3$ replicates per treatment on day 21 .
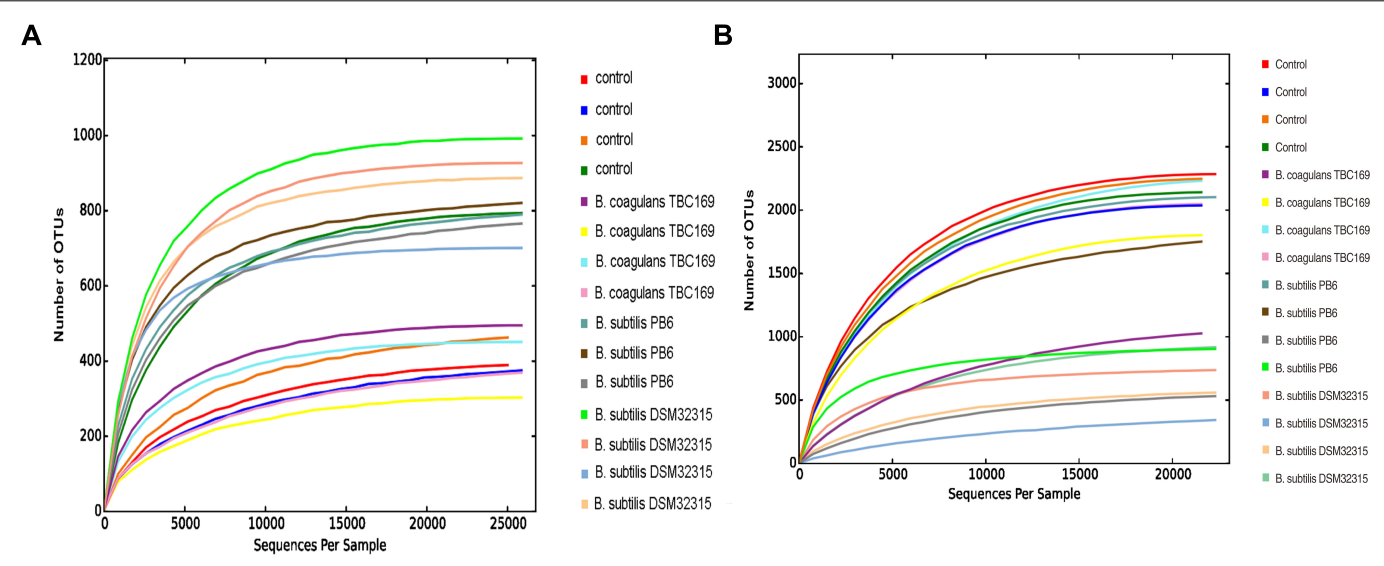

FIGURE 2 | Rarefaction curve of the seven samples. Horizontal axis: the amount of effective sequencing data; vertical axis: the observed number of operational taxonomic units. (A) Day 21 and (B) day 42.

36936 amplicons for each sample (ranging from 30256 to 47874).

As shown in Table 5, probiotics increased $(P<0.004)$ the number of OTUs in the jejunum microbiota at five different taxonomic levels (phylum, class, order, family, genus) on days 21 and 42. On day 21, the microbial abundance in broiler chickens in two $B$. subtilis (B. subtilis PB6 and $B$. subtilis DSM32315) groups was higher $(P<0.01)$ than $B$. coagulans TBC169 group and the control group, whereas there was no difference $(P>0.05)$ between the $B$. coagulans TBC169 group or the control group at five different taxonomic levels (phylum, class, order, family, genus). Two B. subtilis strains (B. subtilis PB6 and B. subtilis DSM32315) improved $(P<0.001)$ the microbial abundance of jejunum in broiler chickens compared with the B. coagulans TBC169 treatment. On day 42, three Bacillus spp. (B. coagulans TBC169, B. subtilis PB6, and B. subtilis DSM32315) influenced $(P<0.004)$ the microbial abundance of jejunum in broiler chickens than the control group at different taxonomic levels. The microbial abundance of broiler chickens in B. subtilis DSM32315 group was lower $(P<0.01)$ than $B$. coagulans TBC169 group and the control group, whereas there was no difference $(P>0.05)$ between two $B$. subtilis strains. The curves of OTU rank and rarefaction were calculated. The rarefaction curves showed that the total richness of the microbial community of all samples achieved a high sampling coverage (Figure 2).

The PCoA and NMDS plot of the jejunum microbiota were based on the weighted UniFrac metric measured as Adonis $(P=0.002$ on day 21 and $P=0.012$ on day 42) and Anosim $(P=0.003$ on day 21 and $P=0.019$ on day 42). These methods showed differences of chickens' microbiota with different probiotics supplementation compared to that of the control (Figure 3). The 


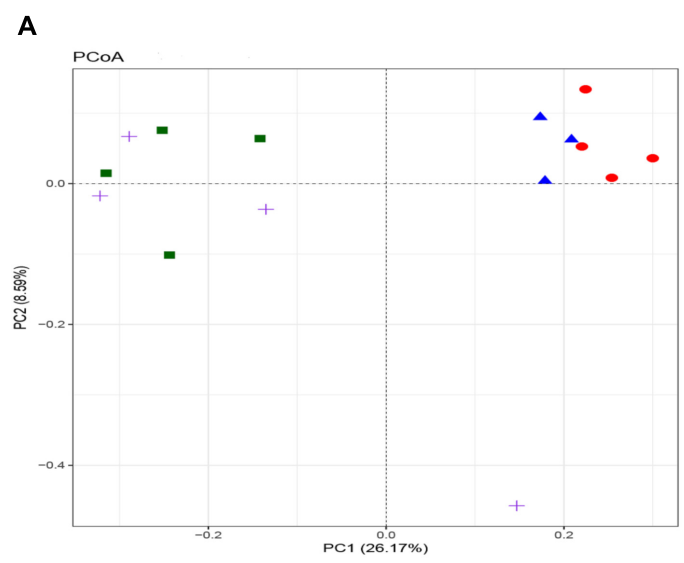

B

C
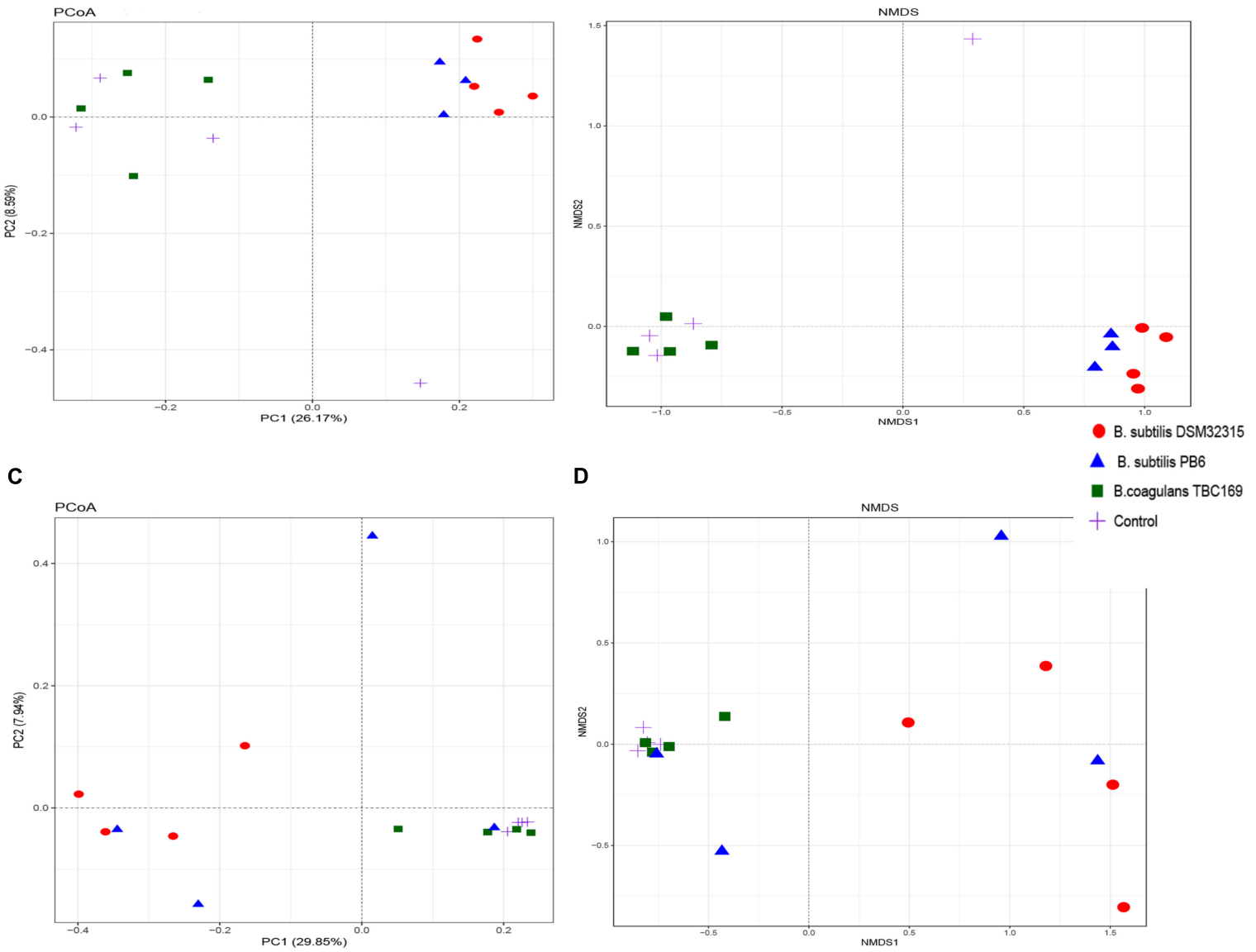

FIGURE 3 | Structural comparison of jejunum microbiota among chicken with different probiotics supplementation. (A) Principal coordinate analysis plot of the jejunum microbiota based on the unweighted UniFracmetric on day 21. (B) Non-metric Multidimensional Scaling on day 21. (C) Principal coordinate analysis plot of the jejunum microbiota based on the unweighted UniFracmetric on day 42. (D) Non-metric Multidimensional Scaling on day 42.

compositions of the jejunal microbiota of the probiotics supplemented chicken were significantly different in comparison to that of the jejunal microbiota of the control.

\section{Impact of Bacillus spp. Supplementation on Microbial Diversity}

Alpha diversity (sample OTU richness) including Simpson index and Shannon index (Table 6) was measured to detect the diversity and structure of jejunal microbial communities with different Bacillus spp. supplementations. According to Shannon and Simpson index, the number of B. subtilis PB6 and $B$. subtilis DSM32315 was higher $(P<0.032)$ than the control on day 21, which illustrated that the jejunum microbial diversity of broiler chickens was greater than the control. But, according to Shannon index, the number of B. subtilis PB6 and $B$. subtilis DSM32315 was higher $(P<0.05)$ than $B$. coagulans TBC169 group. By contrast, on day 42, the figure of the control was the most compared with other treatments, and that was higher $(P<0.05)$ than the supplementation with $B$. subtilis DSM32315.

\section{Impact of Bacillus spp. on the Number of Indicated Taxonomic Rank}

At different taxonomic levels (phylum, class, order, family, and genus), B. subtilis PB6 and B. subtilis DSM32315 increased $(P<0.01)$ the number of indicated taxonomic rank on day 21 , whereas that decreased $(P<0.01)$ the number of indicated taxonomic rank on day 42. The number of indicated taxonomic rank of $B$. coagulans TBC169 group showed no significant differences $(P>0.05)$ compared with the control group on both days 21 and 42 (Table 7).

\section{Impact of Bacillus spp. Supplementation on the Gut Microbial Compositions}

As shown in Figure 4, the phylum level analysis demonstrated that three kinds of Bacillus spp. significantly $(P<0.05)$ influenced the percentage of Firmicutes, Proteobacteria, Bacteroidetes, Actinobacteria, and Acidobacteria on 21 days. The control and all treatments held the largest share in Firmicutes at around $50 \%$ (Figure 3). Meanwhile, the percentage of Firmicutes was higher $(P<0.01)$ in the $B$. coagulans TBC169 group $(70.10 \%)$ 
TABLE 6 | The effect of different sources of Bacillus spp. on diversity index of jejunum microbiota of broiler chickens on days 21 and $42^{1}$.

\begin{tabular}{|c|c|c|c|c|c|}
\hline Items & Control & Bacillus coagulans TBC169 & Bacillus subtilis $\mathrm{PB6}^{2}$ & Bacillus subtilis DSM32315 & $p$-value \\
\hline \multicolumn{6}{|l|}{ Day 21} \\
\hline Simpson & $0.79 \pm 0.03^{a}$ & $0.86 \pm 0.01^{\mathrm{abc}}$ & $0.93 \pm 0.01^{c}$ & $0.91 \pm 0.05^{\mathrm{bc}}$ & 0.032 \\
\hline Shannon & $3.87 \pm 0.33^{a}$ & $4.40 \pm 0.26^{a}$ & $6.14 \pm 0.27^{c}$ & $6.64 \pm 0.42^{c}$ & 0.000 \\
\hline \multicolumn{6}{|l|}{ Day 42} \\
\hline Simpson & $0.99 \pm 0.00$ & $0.89 \pm 0.07$ & $0.83 \pm 0.16$ & $0.54 \pm 0.14$ & 0.071 \\
\hline Shannon & $9.13 \pm 0.13^{a}$ & $7.12 \pm 1.17^{\mathrm{ab}}$ & $6.90 \pm 1.65^{a b}$ & $3.23 \pm 0.88^{c}$ & 0.018 \\
\hline
\end{tabular}

a,b,c Means within a row with no common superscripts differ significantly $(P<0.05) .{ }^{1} n=4$ replicates per treatment. ${ }^{2} n=3$ replicates per treatment on day 21.

TABLE 7 | The effect of different sources of Bacillus spp. on the number of indicated taxonomic rank of broiler chickens on days 21 and $42^{1}$.

\begin{tabular}{|c|c|c|c|c|c|}
\hline Items & Control & Bacillus coagulans TBC169 & Bacillus.subtilis PB6² & Bacillus subtilis DSM32315 & $p$-value \\
\hline \multicolumn{6}{|l|}{ Day 21} \\
\hline Phylum & $18.25 \pm 2.56^{\mathrm{ab}}$ & $15.75 \pm 1.65^{a}$ & $25.33 \pm 0.88^{c}$ & $25.50 \pm 1.19^{c}$ & 0.005 \\
\hline Class & $43.75 \pm 12.09^{a b}$ & $34.00 \pm 5.97^{a}$ & $71.67 \pm 2.33^{\mathrm{C}}$ & $75.50 \pm 3.28^{c}$ & 0.005 \\
\hline Order & $74.00 \pm 19.83^{a}$ & $55.00 \pm 8.22^{a}$ & $124.68 \pm 1.86^{\mathrm{cd}}$ & $132.75 \pm 4.84^{d}$ & 0.002 \\
\hline Family & $125.00 \pm 27.39^{a}$ & $93.50 \pm 10.04^{a}$ & $202.00 \pm 3.61^{c}$ & $212.25 \pm 9.36^{\mathrm{c}}$ & 0.001 \\
\hline Genus & $176.50 \pm 33.44^{a}$ & $145.50 \pm 11.51^{a}$ & $291.00 \pm 4.04^{c}$ & $302.50 \pm 14.33^{c}$ & 0.000 \\
\hline \multicolumn{6}{|l|}{ Day 42} \\
\hline Phylum & $40.00 \pm 0.91^{a}$ & $36.00 \pm 2.92^{a}$ & $28.00 \pm 4.92^{\mathrm{bc}}$ & $22.25 \pm 2.87^{\mathrm{c}}$ & 0.009 \\
\hline Class & $108.75 \pm 4.30^{\mathrm{a}}$ & $97.25 \pm 6.14^{a}$ & $78.50 \pm 12.26^{b c}$ & $64.75 \pm 8.23^{c}$ & 0.011 \\
\hline Order & $155.00 \pm 13.00^{a}$ & $150.50 \pm 9.02^{\mathrm{a}}$ & $114.50 \pm 16.18^{b c}$ & $90.25 \pm 11.85^{\mathrm{c}}$ & 0.004 \\
\hline Family & $190.25 \pm 3.75^{a}$ & $181.25 \pm 13.46^{a}$ & $137.25 \pm 17.88^{b c}$ & $112.50 \pm 13.37^{c}$ & 0.004 \\
\hline Genus & $215.00 \pm 3.03^{a}$ & $203.00 \pm 19.06^{a}$ & $147.00 \pm 24.02^{b c}$ & $111.25 \pm 16.70^{c}$ & 0.004 \\
\hline
\end{tabular}

a,b,c,d Means within a row with no common superscripts differ significantly $(P<0.05) .{ }^{1} n=4$ replicates per treatment. ${ }^{2} n=3$ replicates per treatment on day 21 .

than that in the control group $(47.08 \%)$. As for the rest phyla (Proteobacteria, Bacteroidetes, and Actinobacteria), dietary supplementation with B. subtilis PB6 and B. subtilis DSM32315 group were higher $(P<0.05)$ than both the control and $B$. coagulans TBC169 group, and there were no differences $(P>0.05)$ between the control and B. coagulans TBC169 group. Lactobacillus, which belongs to the phylum of Firmicutes, was the most abundant genus in chicken jejunal microbiota with three kinds of Bacillus spp. supplementation, followed by Bacillus, Lactococcus, and Bacillaceae on day 21. Interestingly, Three kinds of Bacillus spp. tended to decrease $(P=0.077)$ the percentage of Bacillus (phylum of Firmicutes), which was the most abundant genus in the microbiota of chicken jejunum in the control group at the same situation. Dietary supplementation with $B$. subtilis DSM32315 improved $(P<0.01)$ the composition of Clostridiales and Pseudomonas compared control group and B. coagulans TBC169 group at genus level.

The composition of jejunal microflora obviously changed with time. On day 42, the percentage of the phylum of Firmicutes dropped compared with on day 21 , but it still occupied the dominant position in B. subtilis PB6 and B. subtilis DSM32315 groups, followed by Proteobacteria and Acidobacteria (Figure 5). But, the percentage of phylum of Proteobacteria occupied the dominant position in control group and $B$. coagulans TBC169 group, followed by Firmicutes and Acidobacteria. Similarly, Lactobacillus was also the most abundant genus in jejunal microbiota of chicken with three kinds of Bacillus spp. supplementation on day 42 . On the ability of decreasing the percentage of Pseudomonas and Burkholderia, B. subtilis PB6 and B. subtilis DSM32315 were stronger than B.subtilis TBC169, whereas B.subtilis DSM32315 was stronger than B. subtilis TBC169 and B. subtilis PB6 in decreasing the percentage of DA101. The supplementation with probiotics B. subtilis DSM32315 decreased $(P<0.05)$ the percentage of Pseudomonas, Burkholderia, Prevotella, DA101 than control group, whereas the supplementation with probiotics B. subtilis PB6 decreased $(P<0.05)$ the percentage of Burkholderia, Prevotella, DA101 than control group.

A cladogram representative of the structure of the jejunum microbiota and the predominant bacteria were shown in Figure 6. LEfSe detected a marked increase (LDA score > 2) in the relative abundance among the four treatment groups. PLS-DA analysis showed some significant differences in the bacterial composition at genus levels among four treatment groups (Figure 7 ). It shows that bacterial composition on day 21 (Figure 7A) and 42 (Figure 7B) exhibiting the tendency of separation in the profiles among the four treatments and indicating the degree of reliability of PCoA analysis.

Data (Figure 8) from spearman correlation coefficients showed that change of Firmicutes have significantly $(P<0.05)$ positive correlations with growth performance (i.e., BW and ADG), whereas Armatimonadets, Chlorobi, and Cyanobacteria had significantly $(P<0.05)$ negative correlations with BW and ADG at the phylum level on day 21. The changes of 
A

Phylum
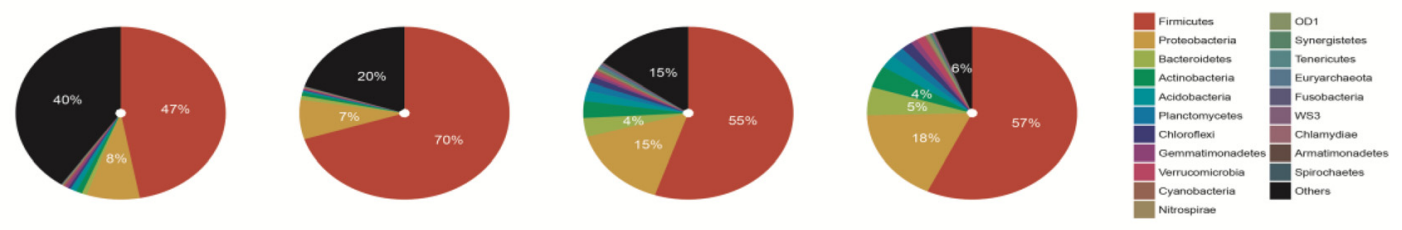

B

Genus
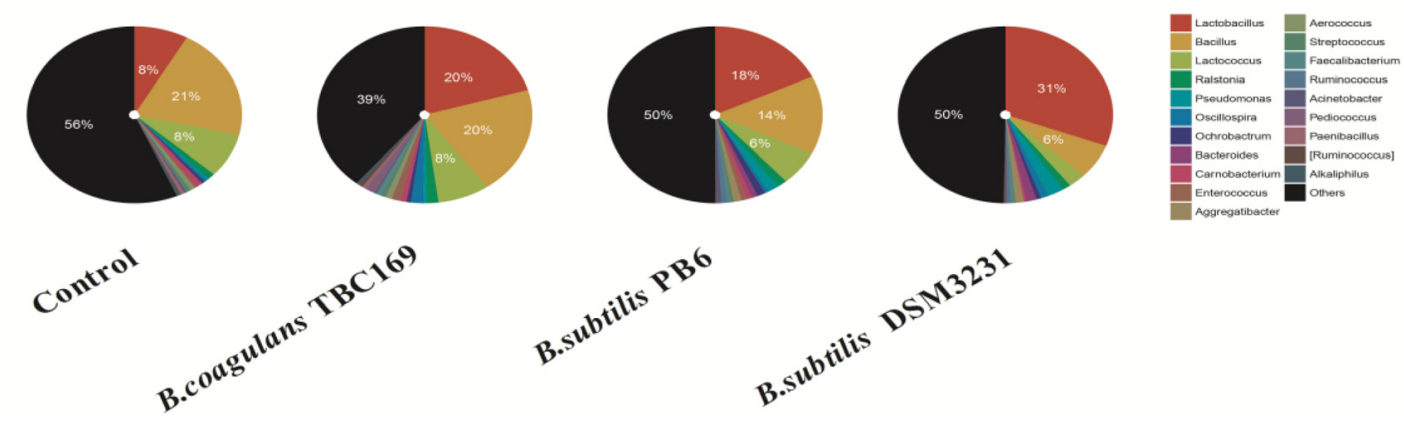

FIGURE 4 | The effect of different sources of Bacillus spp. on gut microbiota composition at different levels (A: Phylum; B: Genus) on day 21.

Macrococcus, Clostridium and Brevundimonas have positive $(P<0.05)$ correlations with BW and ADG, whereas Rhodococcus, Phenylobacterium, Neisseria, Azoarcus, Idiomarina, Erwinia, B42 have significantly negative $(P<0.05)$ correlations with $\mathrm{BW}$ and ADG at the genus level on day 21. Agromyces, Cryocola, JG37-AG-70, Pirellula, Beijerinckia, Amaricoccus, Plesiocystis, Sorangium, Pseudoxanthomonas, Leptonema, and Thermus have positive $(P<0.05)$ correlations with BW and ADG at the genus level on day 42.

\section{DISCUSSION}

Due to the high biological safety and beneficial functions in the regulation of intestinal microflora and micro-ecological balance, $B$. subtilis and B. coagulans have been widely used in the field of animal feed (Selvam et al., 2009; Hung et al., 2012; Pandey and Vakil, 2016). Previous studies indicated that the addition of B. subtilis and B. coagulans as probiotics to broilers' diets can obviously improve the growth performance and FCR (Hung et al., 2012; Jeong and Kim, 2014; Lee K.-W. et al., 2014; Hossain et al., 2015; Li et al., 2016). In this study, B. subtilis PB6, B. subtilis DSM32315 and B. coagulans TBC169 were used for probiotic supplementations in chickens' diets. Although there was no significant difference in ADFI between birds fed diet with probiotics and the control group at the age of 3rd and 6th week, the ADG and BW of birds fed with B. coagulans TBC169 diets were higher than that of chickens fed with the basal diets (Table 2)
$(P<0.05)$. Generally, the reason why the addition of Bacillus spp. can improve the growth performance of broilers is that these probiotics may regulate the composition of intestinal microflora, and exert antibiotics and organic acids to inhibit the survival and colonization of harmful bacteria and further facilitate the balance of intestinal micro-ecosystem (Pedroso et al., 2006). However, the supplementation with $B$. subtilis did not affect the growth performance of chickens including the indexes of ADFI, ADG, and FCR (Table 2) $(P>0.05)$. In addition, there were also reports that dietary B. subtilis failed to improve ADG and decrease FCR in broiler chickens (Knap et al., 2011; Lee K.-W. et al., 2014). The reasons such as the bacterial strains, animal conditions, methods of using probiotics and environmental factors may also contribute to these results (Landy and Kavyani, 2013; Lee S.H. et al., 2014).

In addition, another characteristic of Bacillus spp. is that they can produce various digestive enzymes such as proteases, celluloses and amylases etc. and promoting the transformation of pepsinogen into protease after colonizing in intestinal tract of hosts. They can further stimulate the peristalsis of the intestine to improve nutritional digestion (Giang et al., 2011), which is related to the improvement of broilers' growth performance. A xylanase gene from the chicken caecum has been isolated and over expressed which focused on the potential development of novel and optimized feed additives for industrial use (Al-Darkazali et al., 2017). B. coagulans can produce bacteriocins, which have been widely reported to exhibit antibacterial function in various models (Riazi et al., 2009; Nobutani et al., 2017). Meanwhile, 


\section{day 42}

A

\section{Phylum}
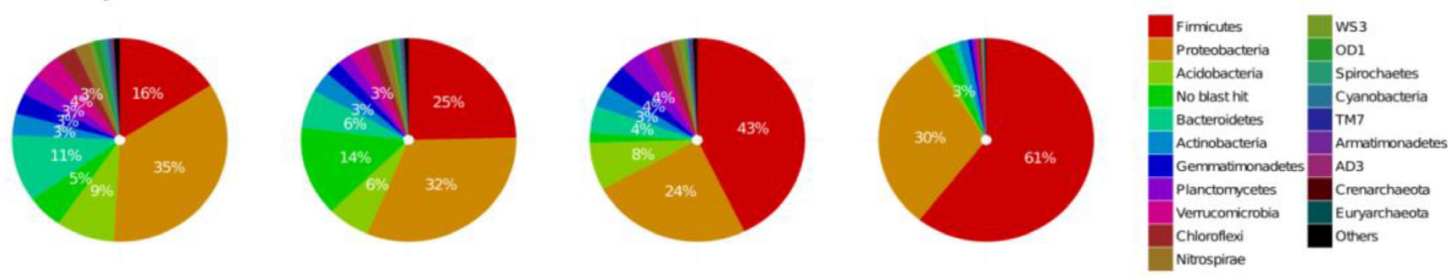

B
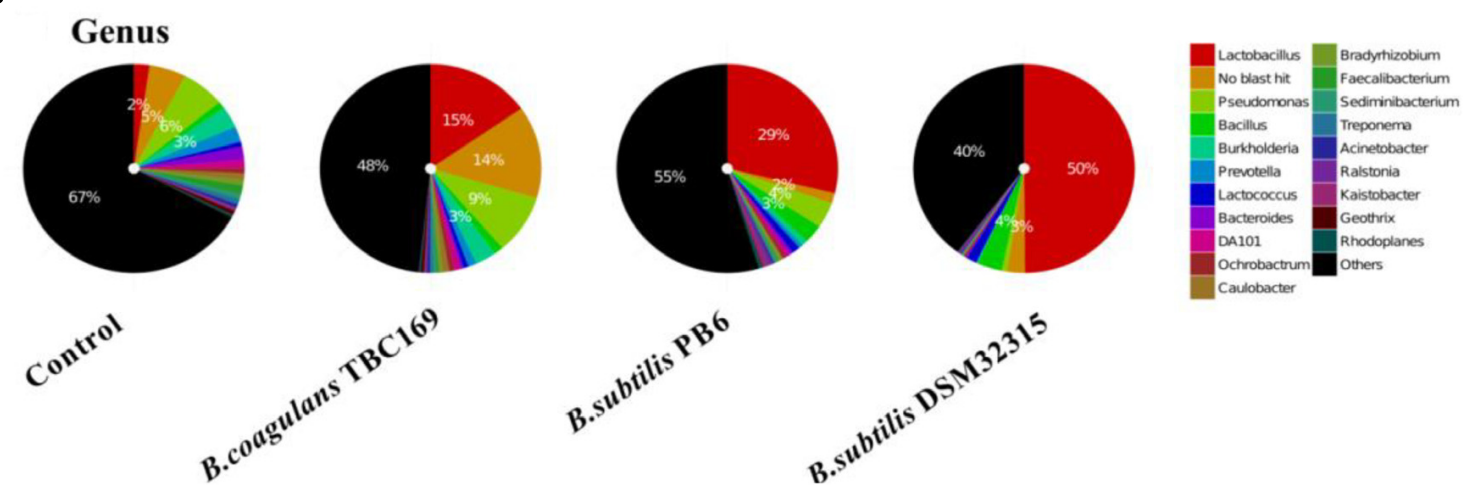

FIGURE 5 | The effect of different sources of Bacillus spp. on gut microbiota composition at different levels (A: Phylum; B: Genus) on day 42.

B. coagulans is associated with lactic acid and other organic acids production, while lactic acid can inhibit gut colonizations of harmful bacteria (Cui et al., 2005) and activate the peristalsis in the intestine to mediate nutrient digestion (Giang et al., 2010; Ma et al., 2014). More recently, B. coagulans-produced dysprosium has been identified to exhibit broad antibacterial spectrum (Honda et al., 2011). Also, B. coagulans can maintain gut microbiota balance via breaking down polysaccharides into oligosaccharides (Zheng et al., 2011). The apparent digestibility of $\mathrm{CP}$ and $\mathrm{GE}$ were higher for birds in the B. coagulans TBC169 treatment group compared with those in the control $(P<0.05)$ in the present study. The ability of improving the apparent total tract digestibility of CP, B.subtilis TBC169 was even stronger than B. subtilis PB6. Dietary B. subtilis DSM32315 supplementation influenced the apparent digestibility of GE (Table 3) $(P=0.05)$. This was in accordance with the findings of Pelícia et al. (2004) who suggested that the improvement in broiler growth performance was likely linked to a better ileal digestibility of nutrients. Similar research reported the increasing levels of dietary supplementation with B. subtilis LS 1-2 product was linked to the improvement in the retention of DM, GE, and CP in broilers (Sen et al., 2012). The dietary supplementation with Bacillus spp. can improve GE and CP digestibility, which is highly associated with gut health and subsequent digestive capacity. The increased $\mathrm{VH}$ and $\mathrm{VH} / \mathrm{CD}$ ratio were directly correlated with an enhanced epithelial turnover (Sen et al., 2012) and high VH and VH/CD ratio suggested an improved intestinal nutrient digestibility and absorption capacity (Montagne et al., 2003). The present study showed that $B$. coagulans TBC169 increased $(P<0.07)$ $\mathrm{VH}$ or $\mathrm{VH} / \mathrm{CD}$ ratio mainly in jejunum compared with the control diet at different phases (Table 4). The B. coagulans TBC169 supplementation might improve the gut structure and further resulted in a greater absorption surface and high-speed turnover of epithelial cells. Similarly, an increase of VH/CD ratio was observed in broilers fed with B. coagulans (Hung et al., 2012). This situation was also consistent with the FCR and BW results in the B. coagulans TBC169 group, which indicated the positive growth performance might be associated with good intestinal morphology. However, at the same condition, the dietary B. subtilis PB6 supplementation improved VH and $\mathrm{VH} / \mathrm{CD}$ ratio only in jejunum compared with the control diet on day 42 . The dietary B. subtilis DSM32315 supplementation did not affect the structure of intestine compared with the control on days 21 and 42 (Table 4). Therefore, different Bacillus spp. has distinguished effects on stimulating the differentiation and proliferation of intestinal epithelial cells and improving nutrient utilization.

This study found that B. subtilis PB6 and B. subtilis DSM32315 more strongly affected the number of indicated taxonomic rank in jejunum microflora than the control or B. coagulans TBC169 group (Table 7). Furthermore, it is generally agreed that the improvement in growth performance and feed conversion efficiency rely on a healthy intestinal morphology, which 

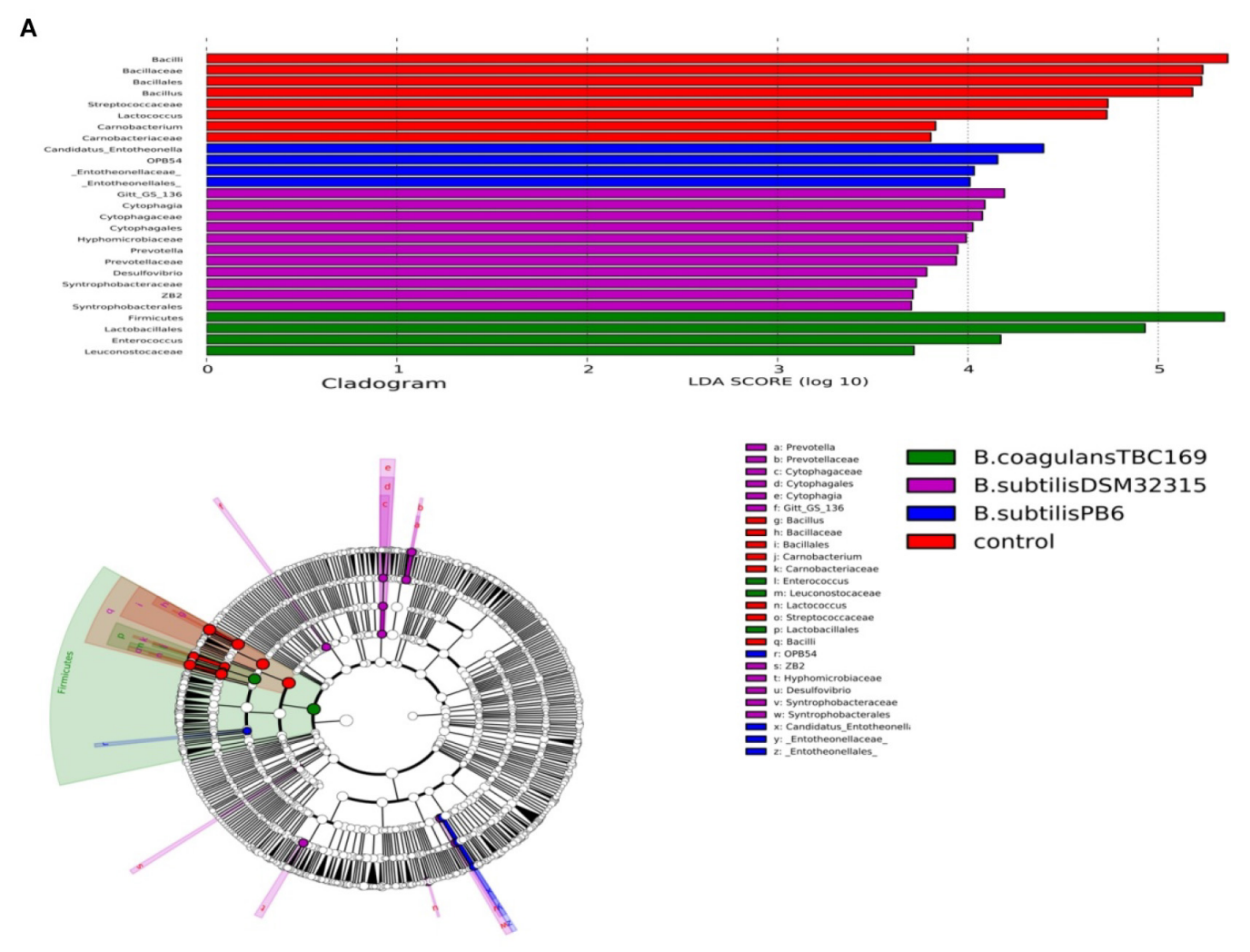

B

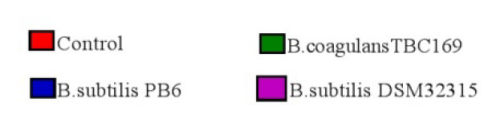

Cladogram
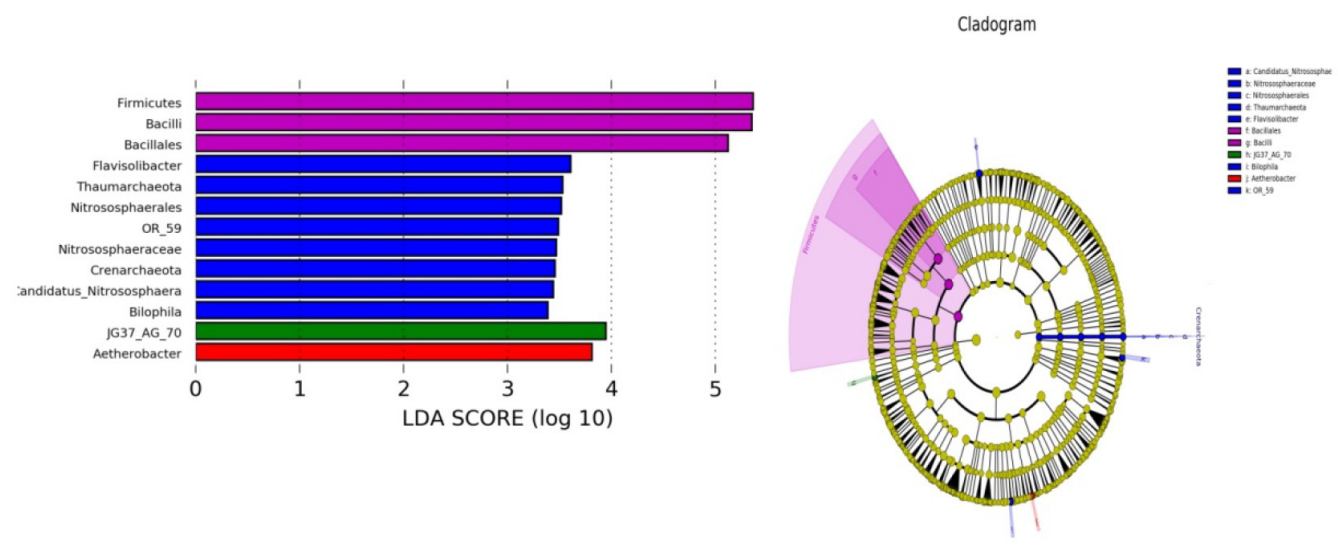

FIGURE 6 | Significantly different taxa between different probiotic stains and control on day 21 (A) and day 42 (B).

may be related to a balance of entire intestinal microflora, resulting in a better intestinal environment (Pedroso et al., 2006; Mountzouris et al., 2010). High-throughput sequencing of the V4 region of the 16S rRNA gene was used for detecting the jejunum microbiota of individual broiler chickens fed diets without or with Bacillus spp. supplementation in the current study. B. subtilis PB6 and B. subtilis DSM32315 treatments exhibited more OTUs than the control on day 21, but the OUTs were higher $(P<0.005)$ in the control compared with other treatments on day 42 (Table 5). In addition, the number of indicated taxonomic rank varied in accordance with OUT variation (Table 7). As the researches exploring the relationship between the growth performance and intestinal microbial composition have become more popular, recent 


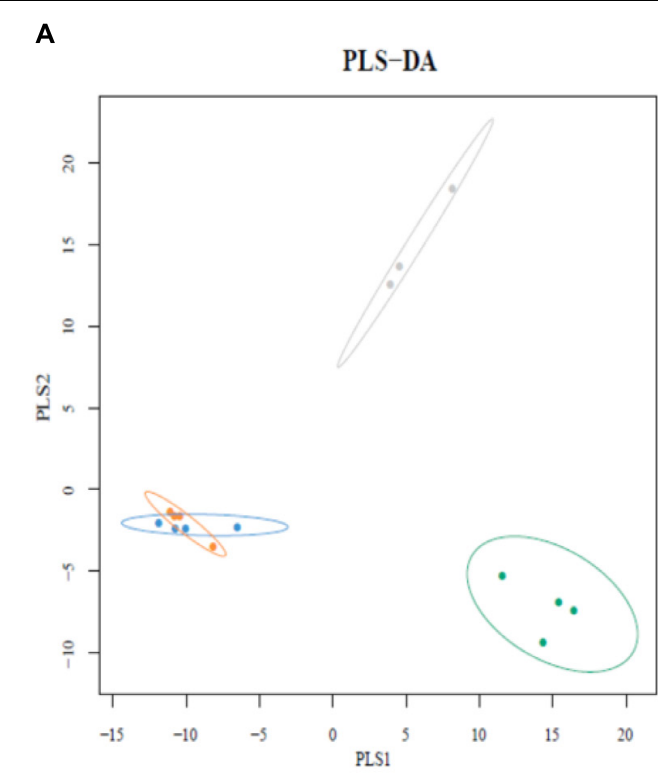

B

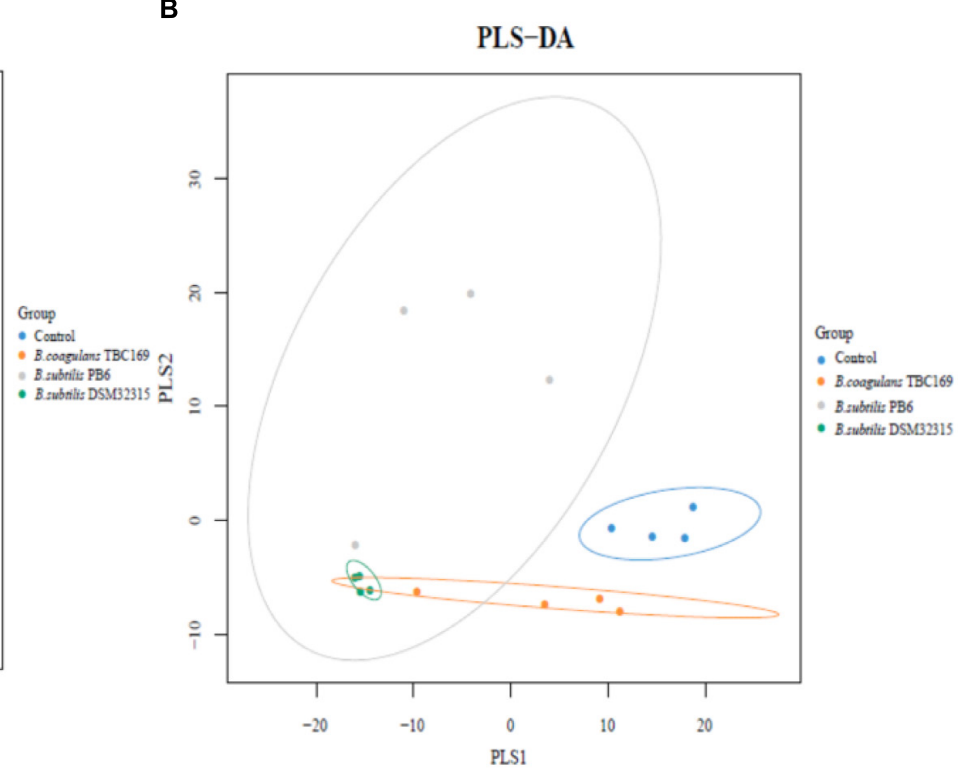

FIGURE 7 | PLS-DA analysis of jejunal digesta collected on day 21 (A) and day 42 (B).

reports showed that alpha index was strongly correlated with diversity (Martiny et al., 2011). Many studies suggested that gut microbiota with high diversity could be more stable and healthier than those with low diversity (Konstantinov et al., 2004). Simpson and Shannon indexes can reflect the community diversity of the microbiota. In this study, Simpson and Shannon indexes showed the similar trend to the number of OTUs (Table 6). B. subtilis PB6 and B. subtilis DSM 32315 treatments enhanced the diversity of jejunal microbiota on day 21 compared with the control $(P \leq 0.032)$. Diet probiotic supplementation influenced diversity of the microbiota according to Simpson and Shannon indexes $(P=0.071$ and $P=0.018)$ on day 42 . Simpson and Shannon index are respond to Bacillus spp. were different on days 21 and 42. The number of Shannon in the treatments with $B$. subtilis DSM32315 was lower $(P<0.05)$ than that in the control. Nevertheless, B. coagulans TBC169 strains did not influence the diversity of jejunal microbiota on days 21 and 42. Changes in taxonomic diversity are the most used indicator to infer changes in microbiological activity, but it is becoming apparent that many of the functions of a normal microbiome can be carried out by a number of microbial groups (Kurokawa et al., 2007; Human Microbiome Project Consortium, 2012). Many studies have shown that the microbial diversity of the chicken microbiota is relatively lower compared to the intestinal microbiota of other animals, which is attributed to the rapid transit of food through the digestive system, with short retention times (Wei et al., 2013). Microbial diversities increased during chicken development, reaching at the peak approximately on day 14 for the foregut and then remaining stable or decreasing slightly thereafter (Huang et al., 2018). Data from a previous study suggest a microbiome more affected by age rather than treatment (Ballou et al., 2016).
The complex microbiota colonized in a chicken' GIT with more than over 900 different bacterial species (Torok et al., 2011). Basically, the most abundant phylum of the chicken intestinal microbiota is Firmicutes (44-55\%), followed by Proteobacteria and Bacteroidetes, which is consistent with the present study (Figures 3, 4) (Qu et al., 2008). However, different sections GIT of chickens are highly interconnected and thus also influence each other's microbiota compositions (Sklan et al., 1978). The composition and function of these communities has been shown to vary depending on the age of the birds, location in the GI tract and on the dietary components (Oakley et al., 2014; Pan and Yu, 2014; Oakley and Kogut, 2016). In addition, the variability in results may be due to sample types (feces vs. cecum), and/or conventional microbiological and molecular methods that have limited coverage and accuracy. The jejunum of a chicken was dominated by Lactobacillus species, mainly L. salivarius and L. aviarius (Gong et al., 2007; Zotta et al., 2017). According to a previous report, at the genus level, Lactobacillus is the predominant genus in the foregut, Lactobacillus provides nutrients to the host and defends against opportunistic pathogens (Huang et al., 2018). Nutrient absorption mainly occurs in the intestine where occupies by a large number of Lactobacillus spp. (Witzig et al., 2015). Various trials have demonstrated that probiotics can positively modulate the composition of the gut microflora of chickens via the stimulation of potentially beneficial populations and the reduction of potentially pathogenic bacteria (Higgins et al., 2008; Hussain et al., 2017b). Dietary inclusion of B. subtilis PB6 and B. subtilis DSM32315 mainly decreased the number of Bacillus genus bacterial and increased lactobacilli population both on days 21 and 42 compared with the control (Figures 3,4$)$. This phenomenon likely illustrated that the three probiotic treatments can regulate the intestinal bacterial flora by increasing the quantity of beneficial bacterial such as lactobacilli 


\section{A Phylum}

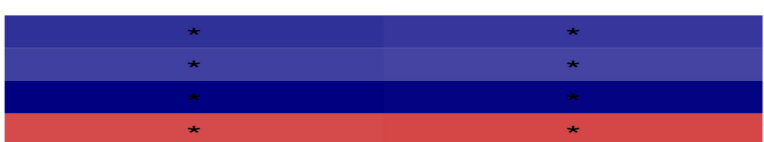

촘

尊

\section{Genus}

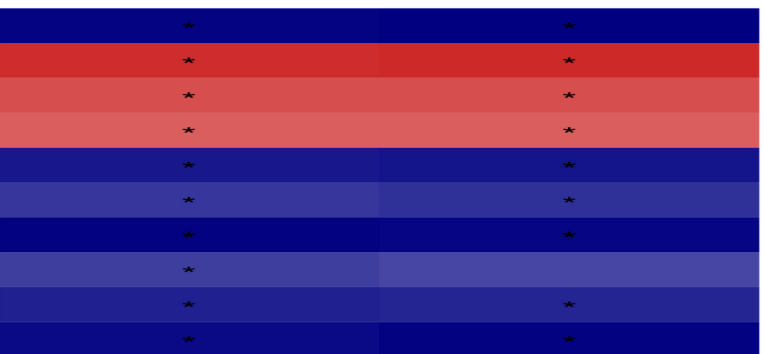

Rhodococcus

Macrococcus

[Clostridium]

Brevundimonas

Phenylobacterium

Neisseria

Azoarcus

Idiomarina

Erwinia

B-42
ฉิ

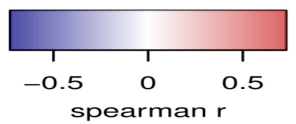

spearman $r$

\section{B Phylum}

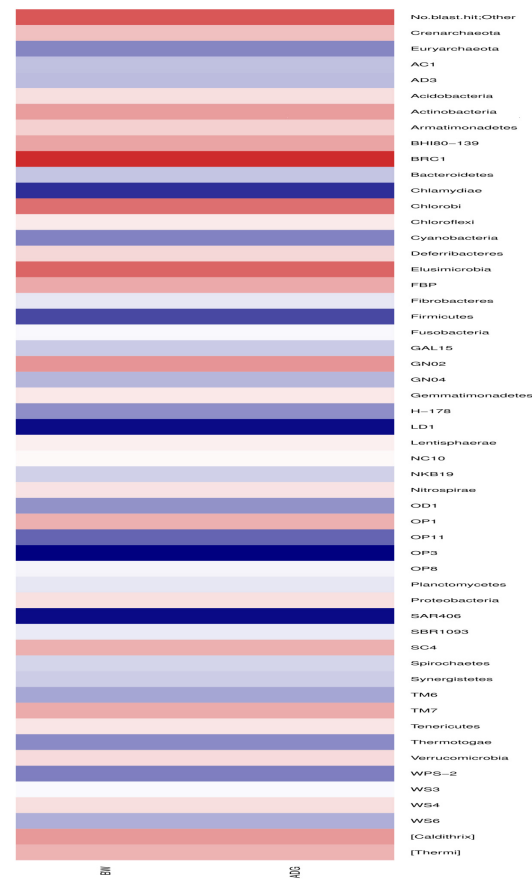

\section{Genus}

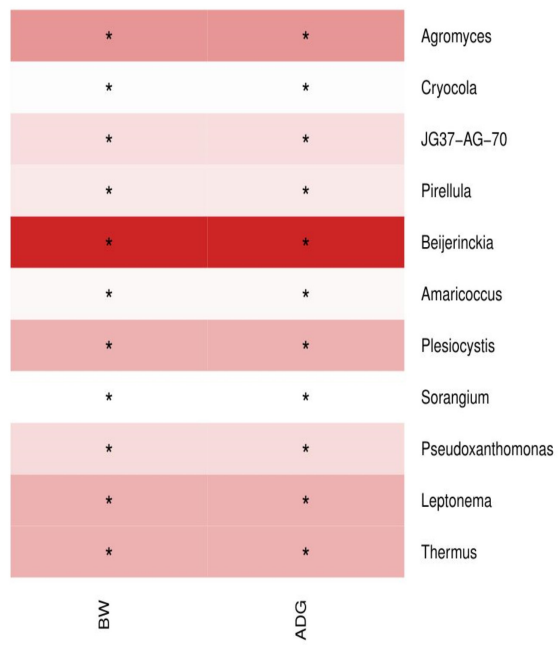

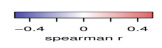

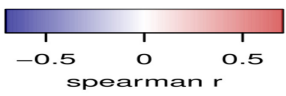

FIGURE 8 | Spearman's rank correlation coefficient between taxonomic change of jejunal microflora because of dietary Bacillus spp. supplementation and growth performance (BW and ADG) on day 21 (A) and day 42 (B). 
and decreasing the number of harmful bacterial like coli bacillus etc. Study have also shown that Bacillus spp. regulated the composition of intestinal bacterial flora, maintained the balance of GIT microflora and improved the immune function of the intestinal mucosa (Isolauri et al., 2001; Barbosa et al., 2005).

Animals with high FCR exhibited a higher abundance of Acinetobacter, Bacteroides, Streptococcus, Clostridium and Lactobacillus whereas Escherichia, Shigella, and Salmonella were more abundant in low FCR animals (Singh et al., 2014). Although the supplementation with probiotics B. subtilis DSM32315 increased $(P<0.05)$ the percentage of Clostridiales than control group on day 21, which did not affect the FCR in the present study. Individual FCR in broiler growers appears to vary, which may in part be due to variation in their gut microbiota. In this paper we analyzed the jejunal microbiota whereas most of the other studies analyzed fecal and cecal microorganisms. Clostridium spp., Enterococcus spp., Streptococcus spp., and Bacteroides spp. were shown to have polysaccharide degrading activity against non-starch polysaccharide (NSPs) found in grain (Beckmann et al., 2006). In mice and humans, Firmicutes have been shown to have a positive relationship with the ability to harvest energy from the diet (Turnbaugh et al., 2006; Jumpertz et al., 2011), and the Firmicutes/Bacteroides ratio may also be important for optimum physiology and nutrition (Bervoets et al., 2013). An increase in fecal Firmicutes was associated with an increase in nutrient absorption, whereas an increase in fecal Bacteroidetes was associated with a decrease in nutrient absorption (Jumpertz et al., 2011). Similar experiments on pig and poultry showed that the increase of Firmicutes abundance and the decrease of Bacteroidetes abundance were positively correlated with the increase of host weight and fat deposition, indicating that intestinal microorganisms were related to the absorption and utilization of energy by the host (Angelakis and Raoult, 2010). In the lowest portion of the small intestine, Lactobacillus spp. have been implicated as a causal factor in low performance (DeLange and Wijtten, 2010), suggesting the location of colonization by probiotic strains may affect performance.

There were many consistencies among the indexes determined in this study. Dietary supplementation with three probiotics

\section{REFERENCES}

Al-Darkazali, H., Meevootisom, V., Isarangkul, D., and Wiyakrutta, S. (2017). Gene expression and molecular characterization of a xylanase from chicken cecum metagenome. Int. J. Microbiol. 8, 1-12. doi: 10.1155/2017/4018398

Altschul, S. F., Madden, T. L., Schaffer, A. A., Zhang, J. H., Zhang, Z., Miller, W., et al. (1997). Gapped BLAST and PSI-BLAST: a new generation of protein database search programs. Nucleic Acids Res. 25, 3389-3402. doi: 10.1093/nar/ 25.17.3389

Angelakis, E., and Raoult, D. (2010). The increase of lactobacillus species in the gut flora of newborn broiler chicks and ducks is associated with weight gain. PLoS One 5:e10463. doi: 10.1371/journal.pone.0010463

Arslan, M., Ozcan, M., Matur, F., Cotelioglu, U., and Ergul, E. (2004). The effect of probiotics on leptin level, body, liver and abdominal fat weights during the rapid growth phase of broilers. Indian Vet. J. 81, 416-420.

Association of Official Analytical Chemists International (2007). Official Methods of Analysis, 18th Edn. Gaithersburg, MD: Association of Official Analytical Chemists. mostly showed the beneficial effects on chicken's growth and intestinal health. Among that, the B. coagulans TBC169 group showed the better growth performance, nutrients digestibility and intestinal morphology compared with the two B. subtilis treatments, while two $B$. subtilis treatments presented more positive variation of the jejunum microflora of chickens than that in the B. coagulans TBC169 group (Figure 7). The possible explanations might be the different characteristics of different strains, the environmental and individual differences etc. In addition, the investigation of jejunum microflora of chickens might not stand for the whole gut microbiota conditions. Therefore, the internal relationships and underlying mechanism are worth further exploring.

\section{CONCLUSION}

Dietary addition of three probiotic Bacillus spp. strains affect body weight and intestinal morphology through altering intestinal microbiota composition in broiler chickens. The findings highlight the importance of intestinal microbiota in mediating the various physiological functions of probiotics in the host. However, the effect of different strains of Bacillus on intestinal microbial composition was different.

\section{AUTHOR CONTRIBUTIONS}

All authors listed have made a substantial, direct and intellectual contribution to the work, and approved it for publication.

\section{FUNDING}

This research was financed by the National Key R\&D Program of China (2018YFD0500600 and 2018YFD0501401), China Agriculture Research System-Beijing Team for Poultry Industry (CARS-PSTP, Beijing, China), and the Agricultural Science and Technology Innovation Program (ASTIP) of the Chinese Academy of Agricultural Sciences.

Azad, A., Sarker, M., Li, T., and Yin, J. (2018). Probiotic species in the modulation of gut microbiota- An Overview. Biomed. Res. Int. 8:9478630. doi: 10.1155/2018/ 9478630

Ballou, A. L., Ali, R. A., Mendoza, M. A., Ellis, J. C., Hassan, H. M., Croom, W. J., et al. (2016). Development of the chick microbiome: how early exposure influences future microbial diversity. Front. Vet. Sci. 3:2. doi: 10.3389/fvets. 2016.00002

Barbosa, T. M., Serra, C. R., La Ragione, R. M., Woodward, M. J., and Henriques, A. O. (2005). Screening for Bacillus isolates in the broiler gastrointestinal tract. Appl. Environ. Microbiol. 71, 968-978. doi: 10.1128/AEM.71.2.968-978.2005

Beckmann, L., Simon, O., and Vahjen, W. (2006). Isolation and identification of mixed linked $\beta$-glucan degrading bacteria in the intestine of broiler chickens and partial characterization of respective 1,3-1,4- $\beta$-glucanase activities. J. Basic Microbiol. 46, 175-185. doi: 10.1002/jobm.200510107

Bervoets, L., Hoorenbeeck, K. V., Kortleven, I., Van Noten, C., Hens, N., Vael, C., et al. (2013). Differences in gut microbiota composition between obese and lean children: a cross-sectional study. Gut Pathog. 5:10. doi: 10.1186/1757-47 49-5-10 
Cao, G. T., Zeng, X. F., Chen, A. G., Zhou, L., Zhang, L., Xiao, Y. P., et al. (2013). Effects of a probiotic, Enterococcus faecium, on growth performance, intestinal morphology, immune response, and cecal microflora in broiler chickens challenged with Escherichia coli K88. Poult. Sci. 92, 2949-2955. doi: $10.3382 /$ ps.2013-03366

Caporaso, J. G., Kuczynski, J., Stombaugh, J., Bittinger, K., Bushman, F. D., Costello, E. K., et al. (2010). QIIME allows analysis of high-throughput community sequencing data. Nat. Methods 7, 335-336. doi: 10.1038/nmeth. f.303

Chao, A., and ShenMing, L. (1992). Estimating the number of classes via sample coverage. J. Am. Stat. Assoc. 87, 210-217. doi: 10.1080/01621459.1992.10475194

Chen, H., and Jiang, W. (2014). Application of high-throughput sequencing in understanding human oral microbiome related with health and disease. Front. Microbiol. 5:508. doi: 10.3389/fmicb.2014.00508

Chen, Y. F., Yang, F. L., Lu, H. F., Wang, B. H., Chen, Y. B., Lei, D. J., et al. (2011). Characterization of fecal microbial communities in Patients with Liver Cirrhosis. Hepatology 54, 562-572. doi: 10.1002/hep.24423

Chitra, P., Mohan, B., and Vishwanathan, K. (2004). Effect of probiotic with ascorbic acid on the growth performance of broilers in summer season. Indian J. Poult. Sci. 39, 281-284.

Clarke, K. R. (1993). Non-parametric multivariate analyses of changes in community structure. Aus. J. Ecol. 18, 117-143. doi: 10.1111/j.1442-9993.1993. tb00438.x

Clavijo, V., and Flórez, M. J. V. (2017). The gastrointestinal microbiome and its association with the control of pathogens in broiler chicken production: a review. Poult. Sci. 97, 1006-1021. doi: 10.3382/ps/pex359

Cui, Y. L., Run, S. C., and Wan, F. C. (2005). Bacteriostasis of Bacillus coagulans TBC 169 to enteropathogenic bacteria. Chin. J. Microecol. 17, 333-338.

Das, H. K., Medhi, A. K., and Islam, M. (2005). Effect of probiotics on certain blood parameters and carcass characteristics of broiler chicken. Indian J. Poult. Sci. 40, 83-86.

DeLange, L. L. M., and Wijtten, P. J. A. (2010). Microbial Profile in the GastroIntestinal Tract of Broilers and its Relation to Feed Efficiency. Australian Poultry Science Symposium. Sydney, NSW: University of Sydney, 3.

Delezie, E., Maertens, L., and Huyghebaert, G. (2012). Consequences of phosphorus interactions with calcium, phytase, and cholecalciferol on zootechnical performance and mineral retention in broiler chickens. Poult. Sci. 91, 2523-2531. doi: 10.3382/ps.2011-01937

DeSantis, T. Z., Hugenholtz, P., Larsen, N., Rojas, M., Brodie, E. L., Keller, K., et al. (2006). Greengenes, a chimera-checked 16S rRNA gene database and workbench compatible with ARB. Appl. Environ. Microbiol. 72, 5069-5072. doi: 10.1128/AEM.03006-05

Edgar, R. C. (2010). Search and clustering orders of magnitude faster than BLAST. Bioinformatics 26, 2460-2461. doi: 10.1093/bioinformatics/btq461

Giang, H. H., Viet, T. Q., Ogle, B., and Lindberg, J. E. (2010). Growth performance, digestibility, gut environment and health status in weaned piglets fed a diet supplemented with potentially probiotic complexes of lactic acid bacteria. Livest Sci. 29, 95-103. doi: 10.1016/j.livsci.2010.01.010

Giang, H. H., Viet, T. Q., Ogle, B., and Lindberg, J. E. (2011). Effects of supplementation of probiotics on the performance, nutrient digestibility and faecal microflora in growing-finishing pigs. Asian Austr. J. Anim. Sci. 24, 655-661. doi: 10.1002/jsfa.9333

Gill, S. R., Pop, M., DeBoy, R. T., Eckburg, P. B., Turnbaugh, P. J., Samuel, B. S., et al. (2006). Metagenomic analysis of the human distal gut microbiome. Science 312, 1355-1359. doi: 10.1126/science.1124234

Gong, J., Si, W., Forster, R. J., Huang, R., Yu, H., Yin, Y., et al. (2007). 16S rRNA gene-based analysis of mucosa-associated bacterial community and phylogeny in the chicken gastrointestinal tracts: from crops to ceca. FEMS Microbiol. Ecol. 59, 147-157. doi: 10.1111/j.1574-6941.2006.00193.x

Haque, M. I., Ahmad, N., and Miah, A. M. (2017). Comparative analysis of body weight and serum biochemistry in broilers supplemented with some selected probiotics and antibiotic growth promoters. Adv, J. Vet. Anim. Res. 4, 288-294. doi: 10.5455/javar.2017.d226

Higgins, S. E., Higgins, J. P., Wolfenden, A. D., Henderson, S. N., Torresrodriguez, A., Tellez, G., et al. (2008). Evaluation of a Lactobacillus-based probiotic culture for the reduction of Salmonella enteritidis in neonatal broiler chicks. Poult. Sci. 87, 27-31. doi: 10.3382/ps.2007-00210
Honda, H., Gibson, G. R., Farmer, S., Keller, D., and Mccartney, A. L. (2011). Use of a continuous culture fermentation system to investigate the effect of GanedenBC30 (Bacillus coagulans GBI-30, 6086) supplementation on pathogen survival in the human gut microbiota. Anaerobe 17, 36-42. doi: 10.1016/j. anaerobe.2010.12.006

Hossain, M. M., Begum, M., and Kim, I. H. (2015). Effect of Bacillus subtilis, Clostridium butyricum and Lactobacillus acidophilus endospores on growth performance, nutrient digestibility, meat quality, relative organ weight, microbial shedding and excreta noxious gas emission in broilers. Vet. Med. 60, 77-86. doi: 10.17221/7981-VETMED

Huang, P., Zhang, Y., Xiao, K. P., Jiang, F., Wang, H. C., Tang, D. Z., et al. (2018). The chicken gut metagenome and the modulatory effects of plant-derived benzylisoquinoline alkaloids. Micobiome 6:211. doi: 10.1186/s40168-0180590-5

Human Microbiome Project Consortium. (2012). Structure, function and diversity of the healthy human microbiome. Nature 486, 207-214. doi: 10.1038/ nature11234

Hung, A. T., Lin, S. Y., Yang, T. Y., Chou, C. K., Liu, H. C., Lu, J. J., et al. (2012). Effects of Bacillus coagulans ATCC 7050 on growth performance, intestinal morphology, and microflora composition in broiler chickens. Anim. Prod. Sci. 52, 874-879. doi: 10.1071/AN11332

Hussain, T., Tan, B., Liu, G., Murtaza, G., Rahu, N., Saleem, M., et al. (2017a). Modulatory mechanism of polyphenols and nrf2 signaling pathway in LPS challenged pregnancy disorders. Oxid. Med. Cell Longev. 2017:8254289. doi: $10.1155 / 2017 / 8254289$

Hussain, T., Tan, B., Ren, W., Rahu, N., Dad, R., Kalhoro, D. H., et al. (2017b). Polyamines: therapeutic perspectives in oxidative stress and inflammatory diseases. Amino Acids 49, 1457-1468. doi: 10.1007/s00726-017-2447-9

Isolauri, E., Sütas, Y., Kankaanp, P., Arvilommiää, H., and Salminen, S. (2001). Probiotics: effects on immunity. Am. Clin. J. Nutr. 73(Suppl. 1), 444S-450S. doi: $10.1093 / \mathrm{ajcn} / 73.2 .444 \mathrm{~s}$

Jeong, J. S., and Kim, I. H. (2014). Effect of Bacillus subtilis C-3102 spores as a probiotic feed supplement on growth performance, noxious gas emission, and intestinal microflora in broilers. Poult. Sci. 93, 3097-3103. doi: 10.3382/ps.201404086

Jumpertz, R., Le, D. S., Turnbaugh, P. J., Trinidad, C., Bogardus, C., Gordon, J. I., et al. (2011). Energy-balance studies reveal associations between gut microbes, caloric load, and nutrient absorption in humans. Am. Clin. J. Nutr. 94, 58-65. doi: 10.3945/ajcn.110.010132

Knap, I., Kehlet, A. B., Bennedsen, M., Mathis, G. F., Hofacre, C. L., Lumpkins, B. S., et al. (2011). Bacillus subtilis (DSM17299) significantly reduces Salmonella in broilers. Poult. Sci. 90, 1690-1694. doi: 10.3382/ps.2010-01056

Konstantinov, S. R., Favier, C. F., Zhu, W. Y., Williams, B. A., Kl, J., Souffrant üß, W. B., et al. (2004). Microbial diversity studies of the porcine gastrointestinal ecosystem during weaning transition. Anim. Res. 53, 317-324. doi: 10.1051/ animres:2004019

Kurokawa, K., Itoh, T., Kuwahara, T., Oshima, K., Toh, H., and Toyoda, A. (2007). Comparative metagenomics revealed commonly enriched gene sets in human gut microbiomes. DNA Res. 14, 169-181. doi: 10.1093/dnares/dsm018

Landy, N., and Kavyani, A. (2013). Effects of using a multi-strain probiotic on performance, immune responses and cecal microflora composition in broiler chickens reared under cyclic heat stress condition. Iran. J. Appl. Anim. Sci. 175, 344-351.

Lee, K.-W., Lillehoj, H. S., Jang, S. I., and Lee, S.-H. (2014). Effects of salinomycin and Bacillus subtilis on growth performance and immune responses in broiler chickens. Res. Vet. Sci. 97, 304-308. doi: 10.1016/j.rvsc.2014.07.021

Lee, S. H., Ingale, S. L., Kim, J. S., Kim, K. H., Lokhande, A., Kim, E. K., et al. (2014). Effects of dietary supplementation with Bacillus subtilis LS 1-2 fermentation biomass on growth performance, nutrient digestibility, cecal microbiota and intestinal morphology of weanling pig. Anim. Feed Sci. Tech. 188, 102-110. doi: 10.1016/j.anifeedsci.2013.12.001

Li, Y., Xu, Q., Huang, Z., Lv, L., Liu, X., Yin, C., et al. (2016). Effect of Bacillus subtilis CGMCC 1.1086 on the growth performance and intestinal microbiota of broilers. Appl. J. Microbiol. 120, 195-204. doi: 10.1111/jam.12972

Li, Z., Wang, W., Liu, D., and Guo, Y. (2017). Effects of Lactobacillus acidophilus on gut microbiota composition in broilers challenged with Clostridium perfringens. PLoS One 12:e188634. doi: 10.1371/journal.pone.0188634 
Lozupone, C., and Knight, R. (2005). UniFrac: a new phylogenetic method for comparing microbial communities. Appl. Environ. Microbiol. 71, 8228-8235. doi: 10.1128/AEM.71.12.8228-8235.2005

Lozupone, C. A., Hamady, M., Kelley, S. T., and Knight, R. (2007). Quantitative and qualitative beta diversity measures lead to different insights into factors that structure microbial communities. Appl. Environ. Microbiol. 73, 1576-1585. doi: 10.1128/AEM.01996-06

Ma, K., Maeda, T. H., You, Y., and Shirai, Y. (2014). Open fermentative production of L-lactic acid with high optical purity by thermophilic Bacillus coagulans using excess sludge as nutrient. Bioresour. Technol. 151, 28-35. doi: 10.1016/ j.biortech.2013.10.022

Magoč, T., and Salzberg, S. L. (2011). FLASH: fast length adjustment of short reads to improve genome assemblies. Bioinformatics 27, 2957-2963. doi: 10.1093/ bioinformatics/btr507

Martiny, J. B., Eisen, J. A., Penn, K., Allison, S. D., and Hornerdevine, M. C. (2011). Drivers of bacterial beta-diversity depend on spatial scale. Proc. Natl. Acad. Sci. U.S.A. 108, 7850-7854. doi: 10.1073/pnas.1016308108

Mashayekhi, H., Mazhari, M., and Esmaeilipour, O. (2018). Eucalyptus leaves powder, antibiotic and probiotic addition to broiler diets: effect on growth performance, immune response, blood components and carcass traits. Animal 12, 2049-2055. doi: 10.1017/S1751731117003731

Mazanko, M. S., Gorlov, I. F., Prazdnova, E. V., Makarenko, M. S., Usatov, A. V., Bren, A. B., et al. (2017). Bacillus probiotic supplementations improve laying performance, egg quality, hatching of laying hens, and sperm quality of roosters. Probiot. Antimicrobiol. Proteins 10, 367-373. doi: 10.1007/s12602-0179369-4

McArdle, B. H., and Anderson, M. J. (2001). Fitting multivariate models to community data: a comment on distance-based redundancy analysis. Ecology 82, 290-297. doi: 10.1890/0012-9658(2001)082[0290:FMMTCD] 2.0.CO;2

Micucci, M., Gotti, R., Corazza, I., Tocci, G., Chiarini, A., De Giorgio, M., et al. (2017). Newer insights into the antidiarrheal effects of acacia catechu willd. extract in guinea pig. J. Med. Food 20, 592-600. doi: 10.1089/jmf.2016. 0154

Montagne, L., Crévieugabriel, I., Toullec, R., and Lallès, J. P. (2003). Influence of dietary protein level and source on the course of protein digestion along the small intestine of the veal calf. Dairy J. Sci. 86, 934-943. doi: 10.3168/jds.S00220302(03)73676-5

Mountzouris, K. C., Tsitrsikos, P., Palamidi, I., Arvaniti, A., Mohnl, M., Schatzmayr, G., et al. (2010). Effect of probiotic inclusion levels in broiler nutrition on growth performance, nutrient digestibility, plasma immunoglobulins, and cecal microflora composition. Poult. Sci. 89, 58-67. doi: 10.3382/ps.2009-00308

Nobutani, K., Sawada, D., Fujiwara, S., Kuwano, Y., Nishida, K., Nakayama, J., et al. (2017). The effects of administration of the Lactobacillus gasseri strain CP2305 on quality of life, clinical symptoms and changes in gene expression in patients with irritable bowel syndrome. J. Appl. Microbiol. 122, 212-224. doi: $10.1111 /$ jam. 13329

Oakley, B. B., and Kogut, M. H. (2016). Spatial and temporal changes in the broilerchicken cecal and fecal microbiomes and correlations of bacterial taxa withcytokine gene expression. Front. Veter. Sci. 3:11. doi: 10.3389/fvets.2016. 00011

Oakley, B. B., Lillehoj, H. S., Kogut, M. H., Kim, W. K., Maurer, J. J., Pedroso, A., et al. (2014). The chicken gastrointestinal microbiome. FEMS. Microbiol. Lett. 360, 100-112. doi: $10.1111 / 1574-6968.12608$

Pan, D., and Yu, Z. T. (2014). Intestinal microbiome of poultry and its interaction with host and diet. Gut Microbes 5, 108-119. doi: 10.4161/gmic.26945

Pandey, K. R., and Vakil, B. V. (2016). Development of bioprocess for high density cultivation yield of the probiotic Bacillus coagulans and its spores. Biosci. J. Biotechnol. 5, 173-181.

Park, J. H., and Kim, I. H. (2014). Supplemental effect of probiotic Bacillus subtilis B2A on productivity, organ weight, intestinal Salmonella microflora, and breast meat quality of growing broiler chicks. Poult. Sci. 93, 2054-2059. doi: 10.3382/ ps.2013-03818

Pedroso, A. A., Menten, J. F., Lambais, M. R., Racanicci, A. M. C., Longo, F. A., Sorbara, J., et al. (2006). Intestinal bacterial community and growth performance of chickens fed diets containing antibiotics. Poult. Sci. 85, 747-752. doi: $10.1093 / \mathrm{ps} / 85.4 .747$
Pelícia, K., Mendes, A. A., Saldanha, E., Pizzolante, C. C., Takahashi, S. E., Garcia, R. G., et al. (2004). Probiotic and prebiotic utilization in diets for freerange broiler chickens. Rev. Bras. Ciênc. Avíc. 6, 99-104. doi: 10.1590/S1516635X2004000200005

Qu, A., Brulc, J. M., Wilson, M. K., Law, B. F., Theoret, J. R., Joens, L. A., et al. (2008). Comparative metagenomics reveals host specific metavirulomes and horizontal gene transfer elements in the chicken cecum microbiome. PLoS One 3:e2945. doi: 10.1371/journal.pone.0002945

Ramette, A. (2007). Multivariate analyses in microbial ecology. FEMS Microbiol. Ecol. 62, 142-160. doi: 10.1111/j.1574-6941.2007.00375.x

Riazi, S., Wirawan, R. E., Badmaev, V., and Chikindas, M. L. (2009). Characterization of lactosporin, a novel antimicrobial protein produced by Bacillus coagulans, ATCC 7050. J. Appl. Microbiol. 106, 1370-1377. doi: 10.1111/ j.1365-2672.2008.04105.x

Segata, N., Izard, J., Waldron, L., Gevers, D., Miropolsky, L., Garrett, W. S., et al. (2011). Metagenomic biomarker discovery and explanation. Genome Biol. 12:R60. doi: 10.1186/gb-2011-12-6-r60

Selvam, R., Maheswari, P., Kavitha, P., Ravichandran, M., Sas, B., and Ramchand, C. N. (2009). Effect of Bacillus subtilis PB6, a natural probiotic on colon mucosal inflammation and plasma cytokines levels in inflammatory bowel disease. Indian J. Biochem. Biol. 46, 79-85.

Sen, S., Ingale, S. L., Kim, Y. W., Kim, J. S., Kim, K. H., Lohakare, J. D., et al. (2012). Effect of supplementation of Bacillus subtilis LS 1-2 to broiler diets on growth performance, nutrient retention, caecal microbiology and small intestinal morphology. Res. Vet. Sci. 93, 264-268. doi: 10.1016/j.rvsc.2011. 05.021

Singh, K. M., Shah, T. M., Beddy, B., Deshpande, S., Rank, D. N., and Joshi, C. G. (2014). Taxonomic and gene-centric metagenomics of the fecal microbiome of low and high feed conversion ratio (FCR) broilers. J. Appl. Genet. 55, 145-154. doi: 10.1007/s13353-013-0179-4

Sklan, D., Shachaf, B., Baron, J., and Hurwitz, S. (1978). Retrograde movement of digesta in the duodenum of the chick: extent, frequency, and nutritional implications. J. Nutr. 108, 1485-1490. doi: 10.1093/jn/108.9.1485

Song, J., Xiao, K., Ke, Y. L., Jiao, L. F., Hu, C. H., Diao, Q. Y., et al. (2014). Effect of a probiotic mixture on intestinal microflora, morphology, and barrier integrity of broilers subjected to heat stress. Poult. Sci. 93, 581-588. doi: 10.3382/ps.201303455

Sun, X., McElroy, A., Webb, K. E. Jr., Sefton, A. E., and Novak, C. (2005). Broiler performance and intestinal alterations when fed drug-free diets. Poult. Sci. 84, 1294-1302. doi: $10.1093 / \mathrm{ps} / 84.8 .1294$

Tallentire, C. W., Leinonen, I., and Kyriazakis, I. (2018). Artificial selection for improved energy efficiency is reaching its limits in broiler chickens. Sci. Rep. 8:1168. doi: 10.1038/s41598-018-19231-2

Torok, V. A., Hughes, R. J., Mikkelsen, L. L., Perez-Maldonado, R., Balding, K., MacAlpine, R., et al. (2011). Identification and characterization of potential performance-related gut microbiotas in broiler chickens across various feeding trials. Appl. Environ. Microbiol. 77, 5868-5878. doi: 10.1128/AEM.001 65-11

Tsukahara, T., Tsuruta, T., Nakanishi, N., Hikita, C., Mochizuki, M., Nakayama, K., et al. (2013). The preventive effect of Bacillus subtilus strain DB9011 against experimental infection with enterotoxcemic Escherichia coli in weaning piglets. Anim. Sci. J. 84, 316-321. doi: 10.1111/asj.12003

Turnbaugh, P. J., Ley, R. E., Mahowald, M. A., Magrini, V., Mardis, E. R., and Gordon, J. I. (2006). An obesity-associated gut microbiome with increased capacity for energy harvest. Nature 444, 1027-1031. doi: 10.1038/nature 05414

Valeriano, V. D., Balolong, M. P., and Kang, D. K. (2017). Probiotic roles of Lactobacillus spp. in swine: insights from gut microbiota. J. Appl. Microbiol. 122, 554-567. doi: 10.1111/jam.13364

Warton, D. I., Wright, S. T., and Wang, Y. (2012). Distance-based multivariate analyses confound location and dispersion effects. Methods Ecol. Evol. 3, 89101. doi: 10.1111/j.2041-210X.2011.00127.x

Wei, S., Morrison, M., and Yu, Z. (2013). Bacterial census of poultry intestinal microbiome. Poult. Sci. Sympos. 92, 671-683. doi: 10.3382/ps.201202822

Witzig, M., Silva, A. C., Engert-Green, R., Hoelzle, K., Zeller, E., Seifert, J., et al. (2015). Spatial variation of the gut microbiota in broiler chickens as affected by dietary available phosphorus and assessed by T-RFLP analysis and 
454 pyrosequencing. PLoS One 10:e0143442. doi: 10.1371/journal.pone.014 3442

Xu, L., Fan, Q., Zhuang, Y., Wan, Q., Gao, Y., and Wang, C. (2017). Bacillus coagulans enhance the immune function of the intestinal mucosa of yellow broilers. Rev. Bras. Cienc. Avic. 19, 115-122. doi: 10.1590/1806-9061-2015-0180

Xu, Q. Q., Yan, H., Liu, X. L., Lv, L., Yin, C. H., Wang, P., et al. (2012). Growth performance and meat quality of broiler chickens supplemented with rhodopseudomonas palustris in drinking water. Asian Austr. J. Anim. Sci. 25, 682-689. doi: 10.1080/00071668.2014.903326

Yang, H., Xiao, Y., Gui, G., Li, J., Wang, J., and Li, D. (2018). Microbial community and short-chain fatty acid profile in gastrointestinal tract of goose. Poult. Sci. 97, 1420-1428. doi: 10.3382/ps/pex438

Yin, J., Han, H., Li, Y., Liu, Z., Zhao, Y., Fang, R., et al. (2017). Lysine restriction affects feed intake and amino acid metabolism via gut microbiome in piglets. Cell Physiol. Biochem. 44, 1749-1761. doi: 10.1159/000485782

Yin, J., Li, Y. Y., Han, H., Chen, S., Gao, J., Liu, G., et al. (2018a). Melatonin reprogramming of gut microbiota improves lipid dysmetabolism in high fat diet-fed mice. J. Pineal Res. 65:e12524. doi: 10.1111/jpi.12524

Yin, J., Li, Y. Y., Han, H., Liu, Z. J., Zeng, X. F., Li, T. J., et al. (2018b). Long-term effects of lysine concentration on growth performance, intestinal microbiome, and metabolic profiles in a pig model. Food Funct. 9, 4153-4163. doi: 10.1039/ c8fo00973b

Zhang, Z. F., Cho, J. H., and Kim, I. H. (2013). Effects of Bacillus subtilis UBT-MO2 on growth performance, immune organ relative weight, fecal gas concentration and intestinal microbial shedding in broiler chickens. Livest Sci. 155, 343-347. doi: 10.1016/j.livsci.2013.05.021
Zheng, Z. J., Ma, C. Q., Gao, C., Li, F. S., Qin, J. Y., Zhang, H. W., et al. (2011). Efficient conversion of phenylpyruvic acid to phenyllactic acid by using whole cells of Bacillus coagulans SDM. PLoS One 6:e19030. doi: 10.1371/journal.pone. 0019030

Zhou, J., Wu, L., Deng, Y., Zhi, X., Jiang, Y. H., Tu, Q., et al. (2011). Reproducibility and quantitation of amplicon sequencing-based detection. ISME J. 5, 13031313. doi: 10.1038/ismej.2011.11

Zhou, X. X., Tian, Z. Q., Wang, Y. B., and Li, W. F. (2010). Effect of treatment with probiotics as water additives on tilapia (Oreochromis niloticus) growth performance and immune response. Fish Physiol. Biochem. 36, 501-509. doi: 10.1007/s10695-009-9320-z

Zotta, T., Parente, E., and Ricciardi, A. (2017). Aerobic metabolism in the genus Lactobacillus: impact on stress response and potential applications in the food industry. Appl. J. Microbiol. 122, 857-869. doi: 10.1111/jam.13399

Conflict of Interest Statement: The authors declare that the research was conducted in the absence of any commercial or financial relationships that could be construed as a potential conflict of interest.

Copyright (c) 2019 Li, Wang, Zhang, Wu, Hui, Yang, Fang and Qi. This is an openaccess article distributed under the terms of the Creative Commons Attribution License (CC BY). The use, distribution or reproduction in other forums is permitted, provided the original author(s) and the copyright owner(s) are credited and that the original publication in this journal is cited, in accordance with accepted academic practice. No use, distribution or reproduction is permitted which does not comply with these terms. 